\title{
Circular intuitionistic fuzzy TOPSIS method with vague membership functions: Supplier selection application context
}

\author{
Cengiz Kahraman ${ }^{1}$ and Nurşah Alkan ${ }^{2}$ \\ ${ }^{1}$ Istanbul Technical University, Industrial Engineering Department \\ 34367, Macka, Besiktas, Istanbul, Turkey \\ ${ }^{2}$ Istanbul Technical University, Industrial Engineering Department \\ 34367, Macka, Besiktas, Istanbul, Turkey
}

Received: 5 February 2021

Accepted: 21 March 2021

\begin{abstract}
The membership function of a general type-2 fuzzy set is three-dimensional in order to incorporate its vagueness through the third dimension. Similarly, Circular intuitionistic fuzzy sets (CIFSs) have been recently introduced by Atanassov (2020) as a new extension of intuitionistic fuzzy sets, which are represented by a circle representing the vagueness of the membership function. CIFSs allow decision-makers to express their judgments including this vagueness. In this study, the TOPSIS method, which is one of the most used multi-criteria decision-making methods is extended to its CIF version. The proposed CIF-TOPSIS methodology is applied to the supplier selection problem. Then, a sensitivity analysis based on criteria weights is conducted to check the robustness of the proposed approach. A comparative analysis with single-valued intuitionistic fuzzy TOPSIS method is also performed to verify the developed approach and to demonstrate its effectiveness.
\end{abstract}

Keywords: Circular intuitionistic fuzzy sets, Intuitionistic fuzzy sets, MCDM, TOPSIS, Supplier selection.

2020 Mathematics Subject Classification: $03 E 72$.

\section{Introduction}

Decision making can be defined as a course of action for selecting the best alternative from a set of alternatives with respect to many criteria to achieve organizational goals [11]. Today, 
Multi-criteria decision making (MCDM) methodology has become the main research area in solving complex decision problems with multiple goals or criteria. Many MCDM techniques such as Analytic Hierarchy Process (AHP) [30], Analytic Network Process (ANP) [31], Technique for Order of Preference by Similarity to Ideal Solution (TOPSIS) [21] and VIseKriterijumska Optimizacija I Kompromisno Resenje (VIKOR) [27] and many others have been developed to solve decision-making problems with many conflicting criteria under uncertainty. Since these classical MCDM techniques require exact numerical values, they are inadequate to handle vagueness and impreciseness in the linguistic assessments. In order to capture this vagueness, MCDM methods have been extended by using ordinary fuzzy sets or their extensions such as intuitionistic fuzzy sets, spherical fuzzy sets, or neutrosophic sets [11].

Starting with Aristotle's logic, multivalued logic has found its ultimate destination with L. A. Zadeh's fuzzy set theory [42]. Ordinary fuzzy sets introduced by Zadeh [42] are represented with a degree of membership and a degree of non-membership which is the complement of membership degree. To deal with these weaknesses of ordinary fuzzy sets, they have been extended to several new extensions by various researchers that describe membership functions with more details. The new extensions of ordinary fuzzy sets are historically shown in Fig. 1.

Criticism of type-1 membership functions led to the development of type-2 fuzzy sets and interval-valued fuzzy sets. Type-2 fuzzy sets have been introduced by Zadeh [43] to handle the vagueness in membership functions as an extension of ordinary fuzzy sets. Then, intuitionistic fuzzy sets (IFSs) were introduced by Atanassov [1], which are composed of a degree of membership and a degree of non-membership whose sum is not necessarily equal to 1 . Their objective is to take the hesitancy of experts into consideration. Hesitant fuzzy sets (HFSs) introduced by Torra [37] have been used to work with a set of potential membership values of an element in a fuzzy set. After the intuitionistic type-2 fuzzy sets (IFS2) were developed by Atanassov [2], Yager [39] called them as Pythagorean fuzzy sets (PFSs) represented with a larger area for membership and non-membership degrees. Later, $q$-rung orthopair fuzzy sets (Q-ROFSs) have been proposed as a general class of IFSs and PFSs by Yager [40]. Neutrosophic sets which have degrees of truthness, indeterminacy, and falsity for each element in the universe have been developed by Smarandache [35]. The sum of these independent three degrees can be at most equal to 3. Picture fuzzy sets and spherical fuzzy sets characterized by the degrees of membership, non-membership, and hesitancy for each element in a set have been introduced as a direct extension of IFSs by Coung [15] and by Kutlu Gündoğdu and Kahraman [18], respectively.

The purpose of all these extensions aims at defining the membership functions in a way that imitates the human thought system. Type-2 fuzzy sets were introduced by Zadeh (1975) so that fuzziness of membership degrees should be incorporated into membership functions as a third dimension. The general purpose of the other fuzzy set extensions is to consider the degree of hesitancy of decision makers rather than adding uncertainty to the membership function. However, the purpose of the recently developed fuzzy set extension circular intuitionistic fuzzy sets (C-IFSs) is to add fuzziness to membership functions, as it is in the type- 2 fuzzy sets. In the literature, there is a need for a MCDM method that fuzzifies the membership function as in type-2 fuzzy sets and that can take into account the hesitancy of decision makers as it is in intuitionistic fuzzy sets. The aim of this paper is to develop CIF-TOPSIS method that takes into account the hesitancy of decision makers and the fuzziness of the membership function. 


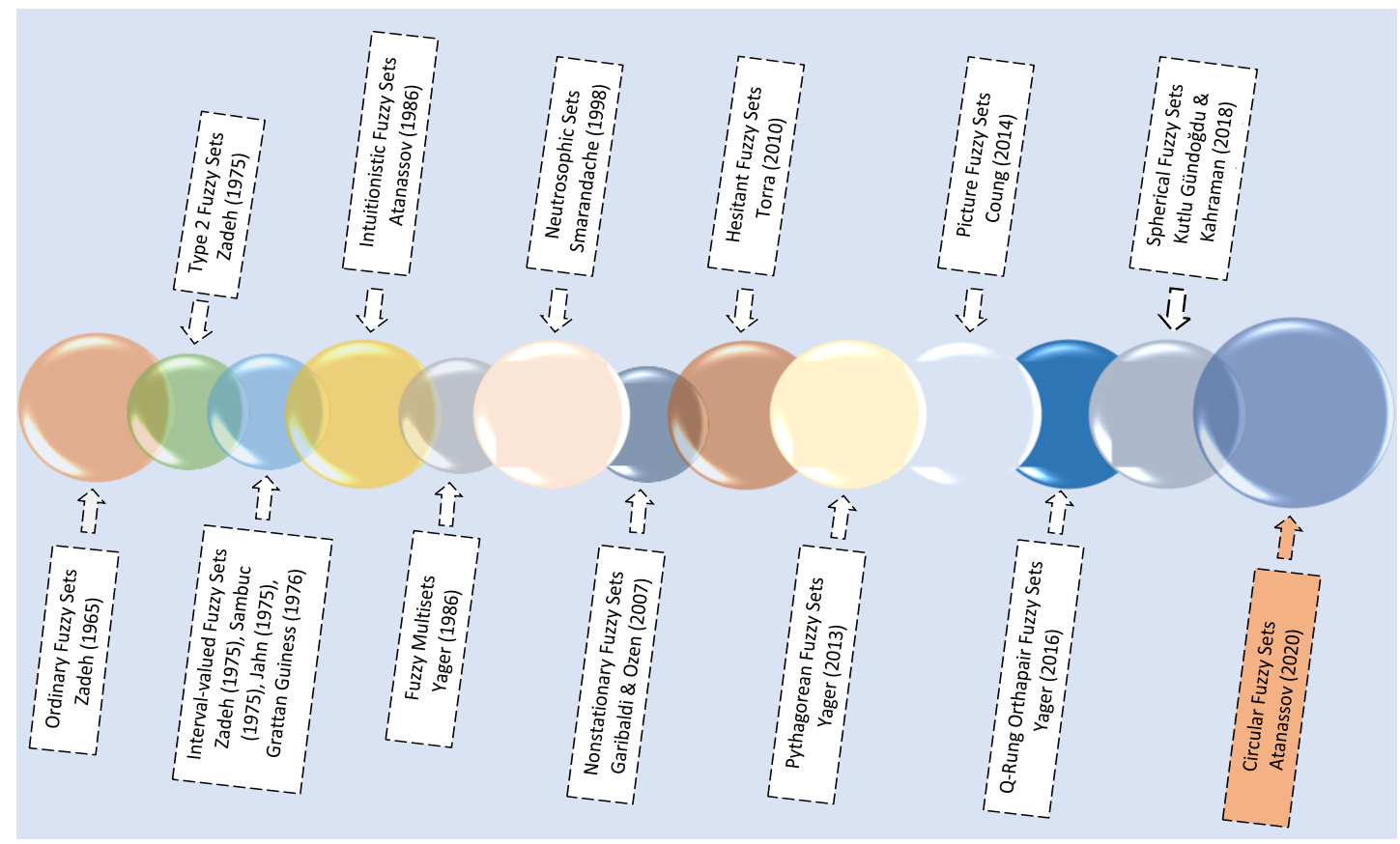

Figure 1. Extensions of fuzzy sets

Intuitionistic fuzzy sets first time incorporated the idea of hesitancy to fuzzy sets. Circular IFSs developed in 2020 by Atanassov [3] are the latest extension of fuzzy sets. Unlike IFSs, each element in a C-IFS is represented by a circle whose center is $\left\langle\mu_{A}(x), v_{A}(x)\right\rangle$ and radius $r$. These sets are defined as the sets where each element of the universe has a degree of membership and a degree of non-membership with a circle around them whose radius is $r$ satisfying that the sum of membership and non-membership degrees within this circle is at most equal to 1. C-IFSs can be used in MCDM methods in order to consider their mentioned features. The originality of this paper comes from the development of the CIF-TOPSIS and its application to the supplier selection problem.

Supplier selection is the process of selecting the best supplier based on several criteria such as financial status, experience, business processes and practices, and product quality to acquire the necessary materials used for producing the products. It is generally based on multiple criteria decision making methods which include both quantitative and qualitative criteria. Vague and imprecise assessments require fuzzy sets to be used in these methods. Especially qualitative criteria are hard to express by exact numerical values. Linguistic terms including vagueness and impreciseness can be represented by fuzzy sets. Most often used multi-criteria decision making methods with fuzzy sets are Analytic Hierarchy Process (AHP), Technique for Order Preference by Similarity to Ideal Solutions (TOPSIS), VIseKriterijumska Optimizacija I Kompromisno Resenje (VIKOR) and ELimination Et Choix Traduisant la REalité (ELECTRE). In this paper, we develop a novel TOPSIS method under circular intuitionistic fuzzy environment and apply it to the supplier selection problem.

The rest of this paper is organized as follows. A literature review on extensions and supplier selection of fuzzy TOPSIS is presented in Section 2. In Section 3, the preliminaries of circular intuitionistic fuzzy sets are given. In Section 4, the proposed MCDM methodology CIF-TOPSIS is presented with its details. In Section 5, the CIF-TOPSIS method is applied to the supplier selection problem and the sensitivity and comparative analyses are presented. Finally, the study ends with the conclusion and suggestions for further researches. 


\section{Literature review}

In this section, we first present a literature review on the fuzzy TOPSIS extensions and then a literature review on supplier selection.

\subsection{TOPSIS method and its fuzzy extensions}

TOPSIS is an Euclidean distance measurement based on MCDM method. The classical TOPSIS method proposed by Hwang and Yoon [21] as a simple and useful MCDM method aiming to choose the best alternative with the shortest distance from the positive ideal solution and the farthest distance from the negative ideal solution. In the classical TOPSIS method, decisionmakers express their opinions by assigning crisp values. However, these crisp values are often insufficient and inadequate for the solution of real decision-making problems when uncertain and vague information is taken into account in decision making [10]. Therefore, classical TOPSIS has been extended to fuzzy TOPSIS to capture the uncertainty in the evaluations of decisionmakers and it has been used in many studies in the literature to address MCDM problems. Along with the new extensions of fuzzy sets, the method has been revealed in different ways by various researchers in recent years such as interval-valued fuzzy TOPSIS [14], intuitionistic fuzzy TOPSIS [8, 26], interval-valued intuitionistic fuzzy TOPSIS [28, 36], hesitant fuzzy TOPSIS [6,38], neutrosophic TOPSIS [7, 16], Pythagorean fuzzy TOPSIS [44], interval-valued Pythagorean fuzzy TOPSIS [41], picture fuzzy TOPSIS [33], $q$-rung orthopair fuzzy TOPSIS [20], spherical fuzzy TOPSIS [18], interval-valued spherical fuzzy TOPSIS [17], Fermatean fuzzy TOPSIS [34]. Sajjad Ali Khan et al. [32] proposed the interval-valued Pythagorean fuzzy Choquet integral geometric (IVPFCIG) operator and, combining the IVPFCIG operator with the Choquet integral-based distance, they developed a TOPSIS method to deal with the multiattribute interval-valued Pythagorean fuzzy group decision-making problems. Liang and Xu [22] developed a new method for hesitant Pythagoras fuzzy clusters (HPFSs) by combining Pythagorean fuzzy sets with hesitant fuzzy sets. In the study, they also introduced the operators of HPFSs and presented the multi-criteria decision-making approach of HPFSs using TOPSIS method. Budak et al. [9] proposed a novel multi-criteria decision-making method that integrates TOPSIS with interval-valued intuitionistic fuzzy sets to select the most appropriate RTLSs technology in a humanitarian relief logistics warehouse. Liu and Rodríguez [24] presented a new representation of the hesitant fuzzy linguistic term sets by means of a fuzzy envelope to carry out the computing-with-words processes. The developed method has been carried out using TOPSIS in the supplier selection problem. Tian et al. developed an innovative multi-criteria group decision-making approach that incorporates power aggregation operators and a TOPSIS-based QUALIFLEX method using neutrosophic linguistic sets for solving green product design selection problems. Ho et al. [19] proposed the (weighted) interval-valued Pythagorean fuzzy (IVPF) correlation-based closeness coefficients to establish a Pearson-like correlation-based TOPSIS model to manage multiple criteria decision analysis problems within the IVPF environment. Kutlu Gündoğdu and Kahraman [18] introduced spherical fuzzy sets and their arithmetic operations, aggregation operators, score and accuracy functions. They also developed a spherical fuzzy TOPSIS method. 


\subsection{Supplier selection}

Supplier selection is a multi-criteria problem which involves both qualitative and quantitative criteria. A tradeoff between these tangible and intangible factors is necessary in order to select the best supplier. Fuzzy sets theory has been used very often in the supplier selection theory and applications. As of the end of 2020, 616 papers on supplier selection are obtained in SCOPUS database when the terms "fuzzy" and "supplier selection" are entered for searching them in manuscript titles. The total number of the manuscripts on "supplier selection" is 2,663 in SCOPUS database. This shows that $25 \%$ of the supplier selection papers are based on the fuzzy set theory. The most cited fuzzy supplier selection papers are pointed out below.

Chen et al. [13] presented a fuzzy decision-making approach to deal with the supplier selection problem in a supply chain system. They used linguistic values whose corresponding membership functions are triangular and trapezoidal in order to assess the ratings and weights for these factors. Then they proposed a fuzzy hierarchical TOPSIS model to deal with the supplier selection problems in the supply chain system. Boran et al. [8] proposed the TOPSIS method combined with intuitionistic fuzzy sets to select an appropriate supplier in a group decision making environment. Intuitionistic fuzzy weighted averaging (IFWA) operator is utilized to aggregate individual opinions of decision makers for rating the importance of criteria and alternatives. Finally, a numerical example for supplier selection is given to illustrate the application of the intuitionistic fuzzy TOPSIS method. Chan et al. [12] discussed some decision variables which can play a critical role in global supplier selection. They used a fuzzy analytic hierarchy process to efficiently handle both quantitative and qualitative decision factors involved in global supplier selection. Lima Junior et al. [23] presented a comparative analysis of fuzzy AHP and fuzzy TOPSIS methods for supplier selection. The results have shown that both methods are suitable for the problem of supplier selection.

In the following, we present some illustrative analyses for all the supplier selection papers and fuzzy supplier selection papers in SCOPUS database. In Fig. 2, the frequencies of all of the supplier selection publications by years are illustrated whereas Fig. 3 illustrates the frequencies of only fuzzy supplier selection publications by years. From Fig. 2 and 3, we understand that a significant increase in supplier selection studies after Year 2006 occurs. The slope of fuzzy publications on supplier selection is larger than that of the classical supplier selection publications.

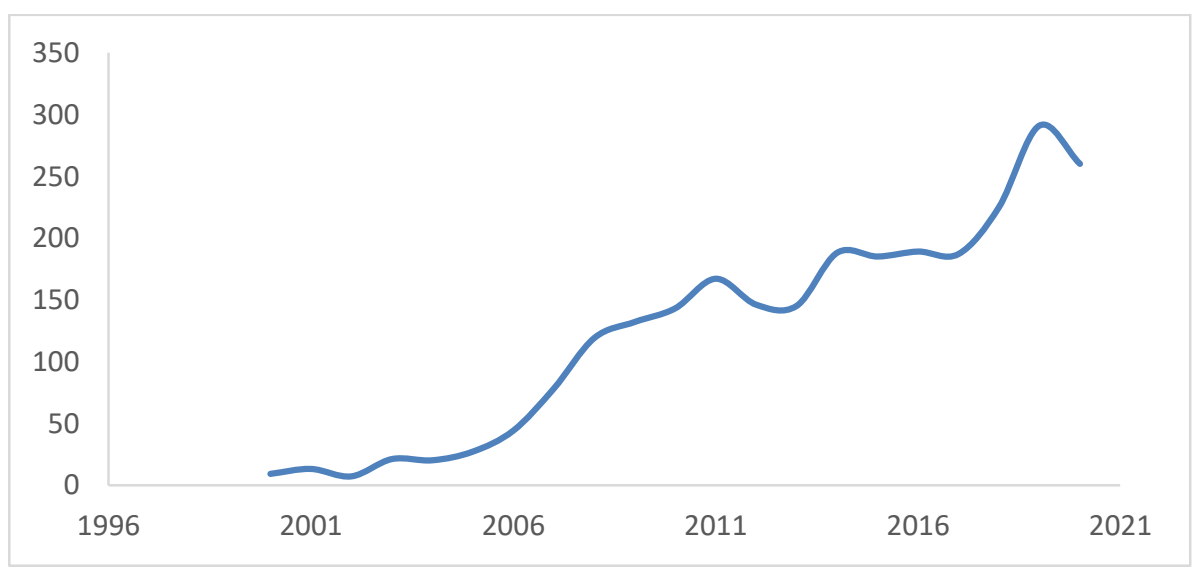

Figure 2. Frequencies of supplier selection publications by years 


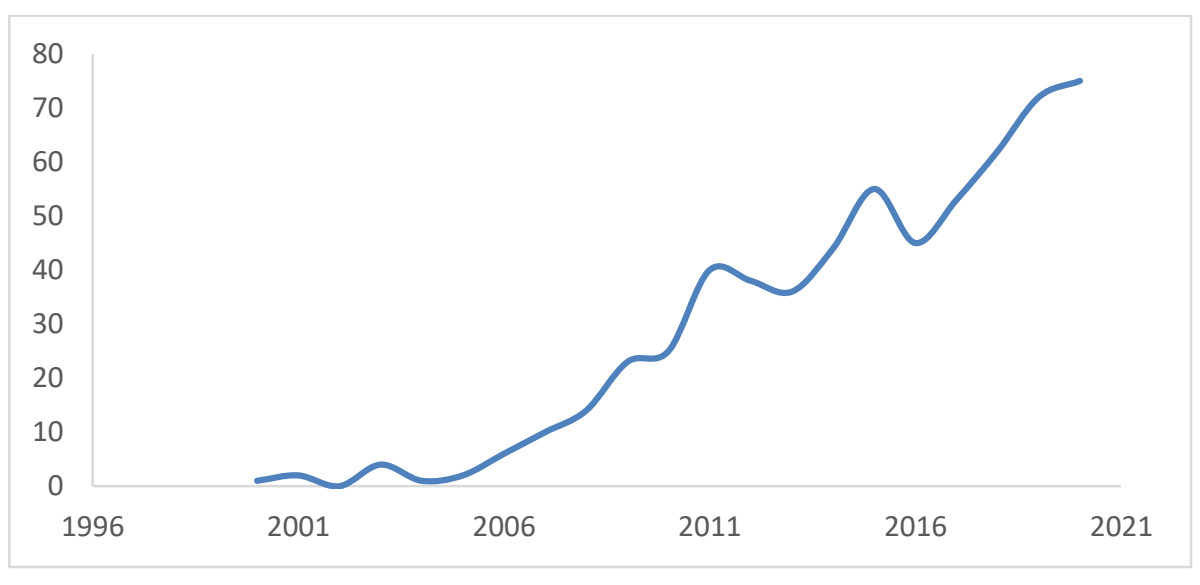

Figure 3. Frequencies of fuzzy supplier selection publications by years

Figures 4 and 5 illustrate the subject areas of all the supplier selection publications and their frequencies and the subject areas of only fuzzy supplier selection publications, respectively. Engineering, computer science, business \& management, decision sciences, and mathematics constitute almost $80 \%$ of the publications. However, in the fuzzy case, decision sciences and mathematics are replaced based on their frequencies.

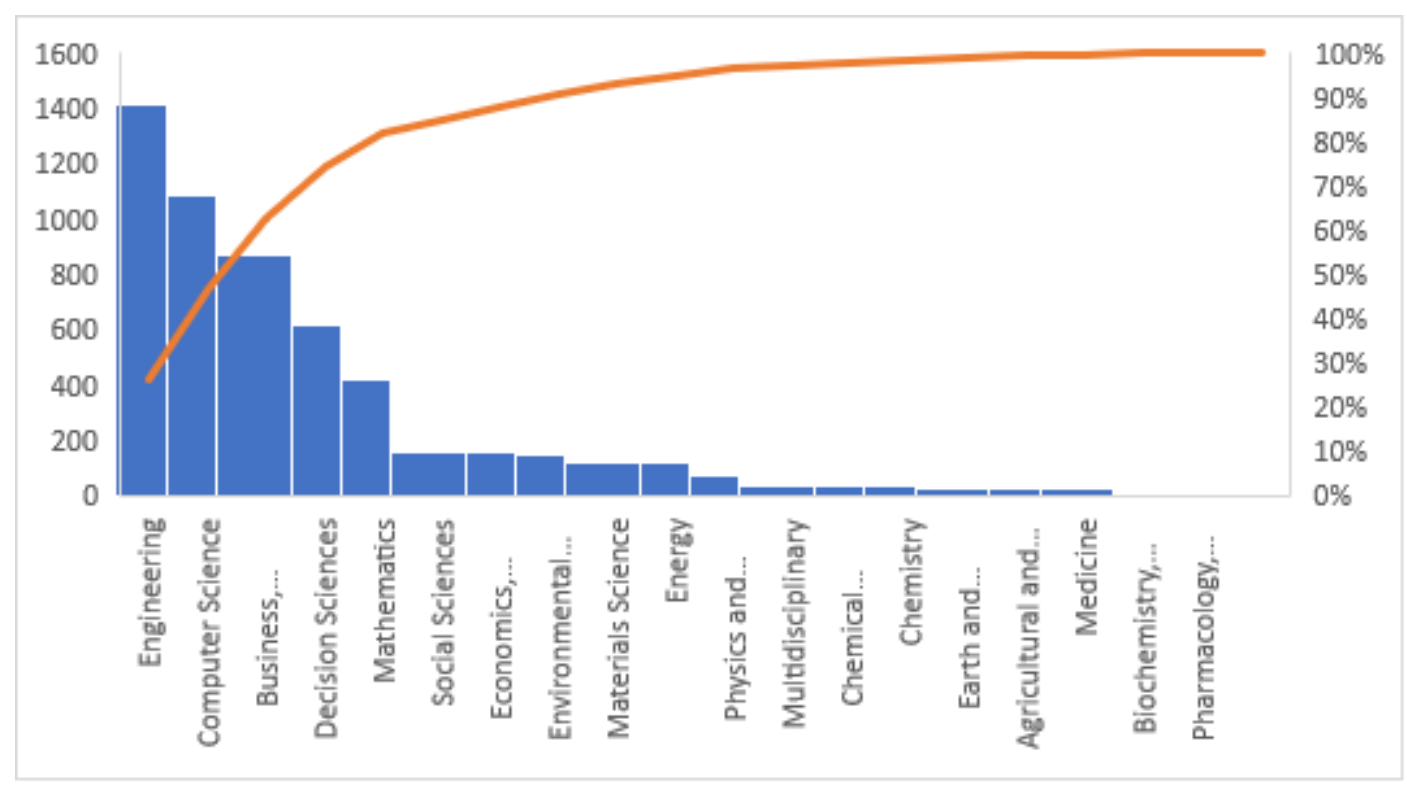

Figure 4. Subject areas of supplier selection publications and their frequencies 


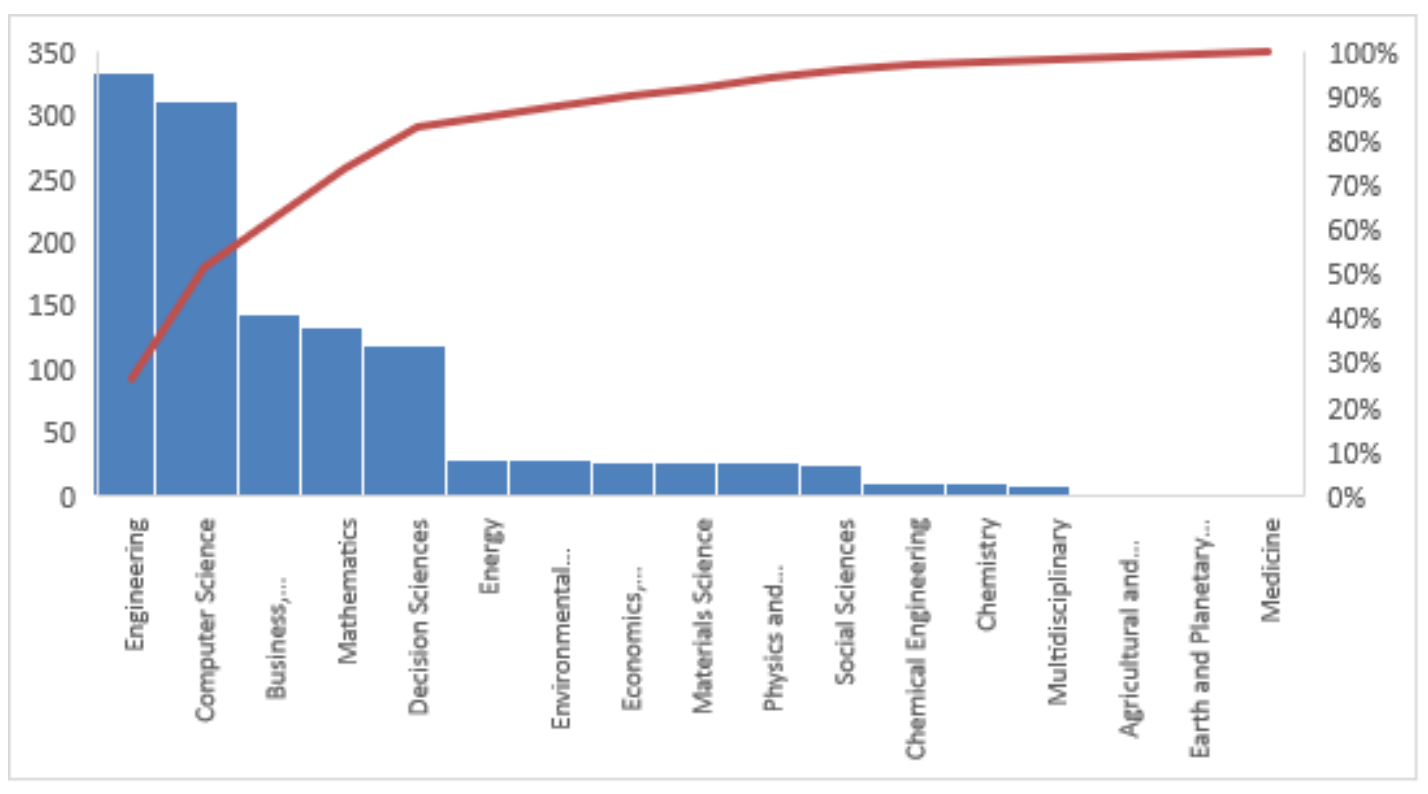

Figure 5. Subject areas of fuzzy supplier selection publications and their frequencies

In supplier selection process, frequently used criteria are production capacity, flexibility, technical capabilities and support, information and communication systems, financial status, and innovation and R\&D, quality systems, management and organization, personnel training and development, performance history, geological location, reputation and references, packaging and handling ability, amount of past business, warranties and claim policies, procedural compliance, attitude and strategic fit, labor relations record, and desire for business, environmental and social responsibility, safety awareness, domestic political stability, cultural congruence with the buyer organization, and terrorism risk, price, quality, timely delivery, the supplier's background, flexibility (Rezaei et al. [29], Bahadori et al. [4], Mahmoudi et al. [25], Beil [5]).

\begin{tabular}{|c|c|}
\hline Criteria & The criteria description \\
\hline Price & $\begin{array}{l}\text { The total price offered by the supplier, including the transportation costs, } \\
\text { discounts, the costs due to delivery delay }\end{array}$ \\
\hline Quality & $\begin{array}{l}\text { Ensuring supply quality in terms of production planning, product durability, } \\
\text { customer satisfaction for sustainability in products and services based on the } \\
\text { quality of finished products and production line }\end{array}$ \\
\hline Performance & $\begin{array}{l}\text { The proper functioning of suppliers during the activity and cooperation and speed } \\
\text { of fulfillment of requests for customers }\end{array}$ \\
\hline Delivery & $\begin{array}{l}\text { The supplier's ability to deliver the desired goods on schedule by providing all } \\
\text { the necessary needs during the raw material reaching the final product }\end{array}$ \\
\hline Flexibility & $\begin{array}{l}\text { The ability of a supplier to meet the change in customer preferences quickly, } \\
\text { produce new products in a short time or change / shorten the delivery time }\end{array}$ \\
\hline Relationship closeness & $\begin{array}{l}\text { The degree to which a supplier provides good after-sales service such as the } \\
\text { seller's attitude to handle complaints, providing problem-solving aids and the } \\
\text { ability and willingness to share the seller's logistics information besides of the } \\
\text { closeness existed between buyer and supplier in early dealings }\end{array}$ \\
\hline $\begin{array}{l}\text { Reputation and market } \\
\text { structured }\end{array}$ & $\begin{array}{l}\text { To be preferred because the reputation of a supplier's brand is that it stems from } \\
\text { years of quality and that suppliers with branded products are more likely to } \\
\text { satisfy their buyers }\end{array}$ \\
\hline
\end{tabular}

Table 1. Evaluation criteria for supplier selection 


\section{Circular intuitionistic fuzzy sets}

Several extensions of intuitionistic fuzzy sets (IFS) have been proposed by various researchers in the literature. The most important of these are Pythagorean fuzzy sets (PFS) and $q$-rung orthopair fuzzy sets ( $q$-ROFS). Finally, Circular IFS, developed by Atanassov [3], is a new extension of IFS. In this section, the basic concepts and the mathematical operations of IFSs, PFSs, $q$-ROFs, and C-IFSs are briefly introduced.

\subsection{Intuitionistic fuzzy sets (IFSs)}

Intuitionistic fuzzy sets have been introduced by Atanassov in 1983 (cf. [1]) as an extension of the ordinary fuzzy sets. IFSs are expressed with a degree of membership and a degree of non-membership for each element in a set that their sum is one or less than one.

Definition 2.1. Let X be a non-empty set. An intuitionistic fuzzy set I in Xis given by:

$$
I=\left\{\left(x, \mu_{I}(x), v_{I}(x)\right) \mid x \in X\right\}
$$

where the functions $\mu_{I}: X \rightarrow[0,1]$ and $v_{I}: X \rightarrow[0,1]$ define the degree of membership and the degree of non-membership of an element to the sets I, respectively, with the condition that

$$
0 \leq \mu_{I}(x)+v_{I}(x) \leq 1 \text {, for } \forall x \in X .
$$

The degree of hesitancy is calculated as follows:

$$
\pi_{I}(x)=1-\mu_{I}(x)-v_{I}(x) .
$$

Definition 2.2. Let $A=\left(\mu_{A}, v_{A}\right)$ and $B=\left(\mu_{B}, v_{B}\right)$ be two IFNs, then the addition and multiplication operations on these two intuitionistic fuzzy numbers (IFNs) are defined by Atanassov as follows:

$$
\begin{gathered}
A \oplus B=\left(\mu_{A}+\mu_{B}-\mu_{A} \mu_{B}, v_{A} v_{B}\right), \\
A \otimes B=\left(\mu_{A} \mu_{B}, v_{A}+v_{B}-v_{A} v_{B}\right) .
\end{gathered}
$$

Definition 2.3. Let $A=\left(\mu_{A}, v_{A}\right)$ be an IFN, then the score function $S(A)$ and accuracy function $H(A)$ of $A$ can be defined as in Eqs. (6) and (7), respectively.

$$
\begin{aligned}
& S(A)=\mu_{A}-v_{A}, \\
& H(A)=\mu_{A}+v_{A} .
\end{aligned}
$$

Definition 2.4. Let $A_{i}=\left(\mu_{A_{i}}, v_{A_{i}}\right)(i=1,2, \ldots, n)$ be a set of IFNs and $w=\left(w_{1}, w_{2}, \ldots, w_{n}\right)^{T}$ be weight vector of $A_{i}$ with $\sum_{i=1}^{n} w_{i}=1$, then an intuitionistic fuzzy weighted geometric (IFWG) operator is

$$
\operatorname{IFWG}\left(A_{1}, A_{2}, \ldots, A_{n}\right)=\left(\prod_{i=1}^{n} \mu_{A_{i}}^{w_{i}},\left(1-\prod_{i=1}^{n}\left(1-v_{A_{i}}\right)^{w_{i}}\right)\right) .
$$

Definition 2.5. Let $A=\left(\mu_{A_{i}}, v_{A_{i}}\right)$ and $B=\left(\mu_{B_{i}}, v_{B_{i}}\right)$ be two IFNs. The distance between these two IFNs is obtained by normalized Euclidean distance as in Eq (8) [2]. 


$$
d(A, B)=\sqrt{\frac{1}{2 n} \sum_{i=1}^{n}\left(\mu_{A_{i}}-\mu_{B_{i}}\right)^{2}+\left(v_{A_{i}}-v_{B_{i}}\right)^{2}+\left(\pi_{A_{i}}-\pi_{B_{i}}\right)^{2}}
$$

\subsection{Circular intuitionistic fuzzy sets}

Circular intuitionistic fuzzy sets (C-IFSs) developed by Atanassov [3] as an extension of the IFSs are represented by a circle of each element that is characterized with degrees of membership and non-membership. C-IFSs are described as demonstrated in Definition 2.6 [3].

Definition 2.6. Let $E$ be a fixed universe. A C-IFS $C_{r}$ in $E$ is an object having the form:

$$
C_{r}=\left\{\left\langle x, \mu_{C}(x), v_{C}(x) ; r\right\rangle \mid x \in E\right\},
$$

where

$$
0 \leq \mu_{C}(x)+v_{C}(x) \leq 1
$$

and $r \in[0,1]$ is a radius of the circle around each element $x \in E$, is called Circular-IFS and the functions $\mu_{C}: E \rightarrow[0,1]$ and $v_{C}: E \rightarrow[0,1]$ represent the degree of membership and the degree of non-membership of the element $x \in E$ to the set $C \subseteq E$, respectively.

The degree of indeterminacy (uncertainty) is calculated as follows:

$$
\pi_{C}(x)=1-\mu_{C}(x)-v_{C}(x) .
$$

In contrast to the standard IFSs, where each element is represented by a point in the intuitionistic fuzzy interpretation triplet, each element in C-IFSs is represented by a circle with center $\left\langle\mu_{C}(x), v_{C}(x)\right\rangle$ and radius $r$.

Definition 2.7. In an IFS $C_{i}$, let intuitionistic fuzzy pairs have the form $\left\{\left\langle m_{i, 1}, n_{i, 1}\right\rangle,\left\langle m_{i, 2}, n_{i, 2}\right\rangle, \ldots\right\}$, where $i$ is the number of IFS $C_{i}$, each including $k_{i}$ IF pairs. Then, the C-IFS is calculated as follows. First, the arithmetic average of the IF pairs is calculated as in Eq. (13).

$$
\left\langle\mu\left(C_{i}\right), v\left(C_{i}\right)\right\rangle=\left\langle\frac{\sum_{j=1}^{k_{i}} m_{i, j}}{k_{i}}, \frac{\sum_{j=1}^{k_{i}} n_{i, j}}{k_{i}}\right\rangle,
$$

where $k_{i}$ is the number of intuitionistic fuzzy pairs in $C_{i}$.

Then, the radius of the $\left\langle\mu\left(C_{i}\right), v\left(C_{i}\right)\right\rangle$ is the maximum of the Euclidean distances given in Eq. (14):

$$
r_{i}=\max _{1 \leq j \leq k_{i}} \sqrt{\left(\mu\left(C_{i}\right)-m_{i, j}\right)^{2}+\left(v\left(C_{i}\right)-n_{i, j}\right)^{2}} .
$$

For a universe $W=\left\{C_{1}, C_{2}, \ldots\right\}$, the C-IFS can be constructed in the following form:

$$
A_{r}=\left\{\left\langle C_{i}, \mu\left(C_{i}\right), v\left(C_{i}\right) ; r\right\rangle \mid C_{i} \in W\right\}=\left\{\left\langle C_{i}, O_{r}\left(\mu\left(C_{i}\right), v\left(C_{i}\right)\right)\right\rangle \mid C_{i} \in W\right\} .
$$

Definition 2.8. Let us have five forms of circles as it is shown in Fig. 6 where the basic geometric interpretation of C-IFS is given.

$$
L^{*}=\{\langle a, b\rangle \mid a, b \in[0,1] \& a+b \leq 1\} .
$$


Therefore, $C_{r}$ can be rewritten in the form

$$
C_{r}^{*}=\left\{\left\langle x, O\left(\mu_{C}(x), v_{C}(x)\right) ; r\right\rangle \mid x \in E\right\},
$$

where $O$ is a function representing a circle, whose radius is $r$ and whose center is $\left(\mu_{C}(x), v_{C}(x)\right)$. $O\left(\mu_{C}(x), v_{C}(x)\right)=\left\{\langle a, b\rangle \mid a, b \in[0,1], \sqrt{\left(\mu_{C}(x)-a\right)^{2}+\left(v_{C}(x)-b\right)^{2}} \leq r\right\} \cap L^{*}=\{\langle a, b\rangle \mid a, b \in[0,1]$, $\left.\sqrt{\left(\mu_{C}(x)-a\right)^{2}+\left(v_{C}(x)-b\right)^{2}} \leq r, a+b \leq 1\right\}$.

C-IFS is an extension of the standard IFS and each standard IFS has the form $C=C_{0}=\left\{\left\langle x, O\left(\mu_{C}(x), v_{C}(x)\right) ; 0\right\rangle \mid x \in E\right\}$, therefore, C-IFS with $r>0$ cannot be represented by a standard IFS.

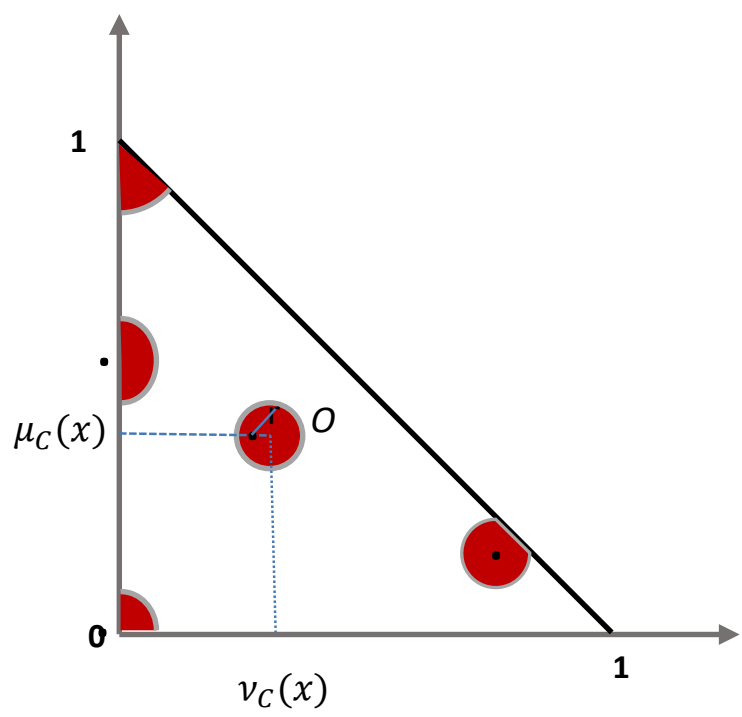

Figure 6. C-IFS geometrical representation

Definition 2.9. Let $C_{1}=\left\langle\mu_{C_{1}}(x), v_{C_{1}}(x) ; r_{1}\right\rangle$ and $C_{2}=\left\langle\mu_{C_{2}}(x), v_{C_{2}}(x) ; r_{2}\right\rangle$ be two circular intuitionistic fuzzy numbers. The operations given here are based on the minimum and maximum of the radiuses separately since they give the results with minimum and maximum level of uncertainty, respectively. A smaller radius represents smaller vagueness whereas a larger radius represents larger vagueness for IF pairs. Their operations can be defined as follows:

$$
\begin{aligned}
& C_{1} \cap_{\text {min }} C_{2}=\left\{\left\langle x, \min \left(\mu_{C_{1}}(x), \mu_{C_{2}}(x)\right), \max \left(v_{C_{1}}(x), v_{C_{2}}(x)\right) ; \min \left(r_{1}, r_{2}\right)\right\rangle \mid x \in E\right\}, \\
& C_{1} \cap_{\text {max }} C_{2}=\left\{\left\langle x, \min \left(\mu_{C_{1}}(x), \mu_{C_{2}}(x)\right), \max \left(v_{C_{1}}(x), v_{C_{2}}(x)\right) ; \max \left(r_{1}, r_{2}\right)\right\rangle \mid x \in E\right\}, \\
& C_{1} \cup_{\min } C_{2}=\left\{\left\langle x, \max \left(\mu_{C_{1}}(x), \mu_{C_{2}}(x)\right), \min \left(v_{C_{1}}(x), v_{C_{2}}(x)\right) ; \min \left(r_{1}, r_{2}\right)\right\rangle \mid x \in E\right\}, \\
& C_{1} \cup_{\text {max }} C_{2}=\left\{\left\langle x, \max \left(\mu_{C_{1}}(x), \mu_{C_{2}}(x)\right), \min \left(v_{C_{1}}(x), v_{C_{2}}(x)\right) ; \max \left(r_{1}, r_{2}\right)\right\rangle \mid x \in E\right\}, \\
& C_{1} \oplus_{\min } C_{2}=\left\{\left\langlex, \mu_{C_{1}}(x)+\mu_{C_{2}}(x)-\mu_{C_{1}}(x) * \mu_{C_{2}}(x), v_{C_{1}}(x)\right.\right. \\
&\left.\left.* v_{C_{2}}(x) ; \min \left(r_{1}, r_{2}\right)\right\rangle \mid x \in E\right\}, \\
& C_{1} \oplus_{\max } C_{2}=\left\{\left\langlex, \mu_{C_{1}}(x)+\mu_{C_{2}}(x)-\mu_{C_{1}}(x) * \mu_{C_{2}}(x), v_{C_{1}}(x)\right.\right. \\
&\left.\left.* v_{C_{2}}(x) ; \max \left(r_{1}, r_{2}\right)\right\rangle \mid x \in E\right\},
\end{aligned}
$$




$$
\begin{aligned}
C_{1} \otimes_{\min } C_{2}= & \left\{\left\langlex, \mu_{C_{1}}(x) * \mu_{C_{2}}(x), v_{C_{1}}(x)+v_{C_{2}}(x)-v_{C_{1}}(x)\right.\right. \\
& \left.\left.* v_{C_{2}}(x) ; \min \left(r_{1}, r_{2}\right)\right\rangle \mid x \in E\right\}, \\
C_{1} \otimes_{\max } C_{2}= & \left\{\left\langlex, \mu_{C_{1}}(x) * \mu_{C_{2}}(x), v_{C_{1}}(x)+v_{C_{2}}(x)-v_{C_{1}}(x)\right.\right. \\
& \left.\left.* v_{C_{2}}(x) ; \max \left(r_{1}, r_{2}\right)\right\rangle \mid x \in E\right\} .
\end{aligned}
$$

\section{Circular intuitionistic fuzzy TOPSIS}

In this section, a novel circular intuitionistic fuzzy TOPSIS method is introduced. The framework of the proposed approach has been given in the flowchart in Fig. 7. The steps of the proposed new TOPSIS method are detailed theoretically in the following steps.

Step 1. Determine the alternatives, relevant criteria, and decision-makers (DMs) to construct the framework of the application. The set of alternatives $A=\left\{A_{1}, A_{2}, \ldots, A_{i}, \ldots, A_{m}\right\}$, $i=1,2, \ldots, m$, is assessed by a set of decision criteria $C=\left\{C_{1}, C_{2}, \ldots, C_{j}, \ldots, C_{n}\right\}$, $j=1,2, \ldots, n$. Let $w=\left(w_{1}, w_{2}, \ldots, w_{n}\right)$ be the vector set used for defining the criteria weights, where $w_{j}>0$ and $\sum_{j=1}^{n} w_{j}=1$. DMs are represented by $D M_{1}, D M_{2}, \ldots, D M_{k}$ who are experts in their fields to make judgments.

Step 2. Construct the decision matrices consisting of linguistic terms with respect to DMs' opinions by using the scale given in Table 2. Each DM fills in the decision matrix by using the linguistic scale.

Step 3. Convert the linguistic data to their corresponding IFNs using Table 2. Through the scale, the decision matrix consisting of the intuitionistic fuzzy pairs $\left(D_{k}\right)$ with respect to DM $k$ is given in Table 3. Here, $\widetilde{D}_{k}=\left(\tilde{d}_{i j k}\right)_{n x m}$ in which $\tilde{d}_{i j k}=\left(m_{i j k}, n_{i j k}\right)$ is constructed by utilizing the IFNs given in Table 2 . Accordingly, $\tilde{d}_{i j k}$ indicates the performance of alternative $A_{i}$ in terms of criterion $C_{j}$ of $k^{\text {th }} \mathrm{DM}$.

\begin{tabular}{lcc}
\hline \multirow{2}{*}{ Linguistic terms } & \multicolumn{2}{c}{ IFNs for alternatives } \\
\cline { 2 - 3 } & $\boldsymbol{m}$ & $\boldsymbol{n}$ \\
\hline Certainly High Value - (CHV) & 0.9 & 0.1 \\
Very High Value - (VHV) & 0.8 & 0.15 \\
High Value - (HV) & 0.7 & 0.25 \\
Above Average Value - (AAV) & 0.6 & 0.35 \\
Average Value - (AV) & 0.5 & 0.45 \\
Under Average Value - (UAV) & 0.4 & 0.55 \\
Low Value - (LV) & 0.3 & 0.65 \\
Very Low Value - (VLV) & 0.2 & 0.75 \\
Certainly Low Value - (CLV) & 0.1 & 0.9 \\
\hline
\end{tabular}

Table 2. IF Linguistic scale for ratings of alternatives 


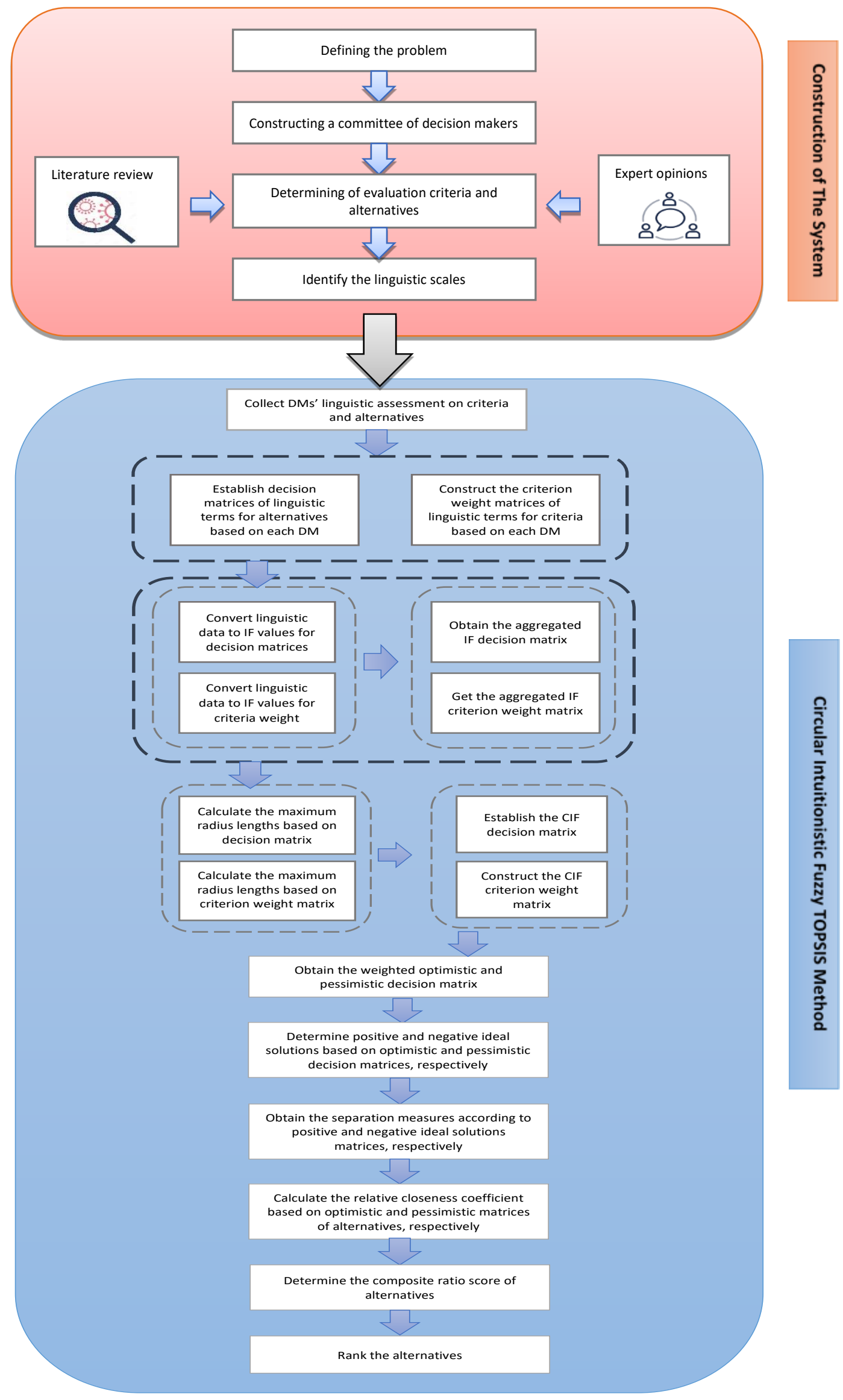

Figure 7. Framework of the proposed approach 


\begin{tabular}{ccccc}
\hline \multirow{2}{*}{ Criteria } & \multicolumn{4}{c}{ Alternatives } \\
\cline { 2 - 5 } & $A_{1}$ & $A_{2}$ & $\ldots$ & $A_{m}$ \\
\hline$C_{1}$ & $\left\langle\left(m_{11 k}, n_{11 k}\right)\right\rangle$ & $\left\langle\left(m_{12 k}, n_{12 k}\right)\right\rangle$ & $\ldots$ & $\left\langle\left(m_{1 m k}, n_{1 m k}\right)\right\rangle$ \\
$C_{2}$ & $\left\langle\left(m_{21 k}, n_{21 k}\right)\right\rangle$ & $\left\langle\left(m_{22 k}, n_{22 k}\right)\right\rangle$ & $\ldots$ & $\left\langle\left(m_{2 m k}, n_{2 m k}\right)\right\rangle$ \\
$\vdots$ & $\vdots$ & $\vdots$ & $\ddots$ & $\vdots$ \\
$C_{n}$ & $\left\langle\left(m_{n 1 k}, n_{n 1 k}\right)\right\rangle$ & $\left\langle\left(m_{n 2 k}, n_{n 2 k}\right)\right\rangle$ & $\ldots$ & $\left\langle\left(m_{n m k}, n_{n m k}\right)\right\rangle$ \\
\hline
\end{tabular}

Table 3. Decision matrix based on intuitionistic fuzzy numbers with respect to $\mathrm{DM}_{k}$

Step 4. Obtain the aggregated intuitionistic fuzzy decision matrix using the decision matrices consisting of intuitionistic fuzzy pairs. The intuitionistic fuzzy pairs in individual decision matrices are converted to the aggregated intuitionistic fuzzy numbers using Eq. (13).

Step 5. Calculate the maximum radius lengths $R^{D}=\left(r_{i j}^{d}\right)_{n \times m}$ based on the decision matrices of all DMs using Eq. (14). The maximum radius lengths are found by considering the radius lengths obtained by each DM evaluating the $i$-th alternative according to the $j$-th criterion. Then, the circular intuitionistic fuzzy decision matrix $(\widetilde{D})$ is constructed as in Table 4. Here, $\widetilde{D}=\left(\tilde{d}_{i j}\right)_{n \times m}$ in which $\tilde{d}_{i j}=\left(\mu_{i j}, v_{i j}, r_{i j}\right)$ is used to indicate the circular intuitionistic fuzzy number of the $i$-th alternative with respect to the $j$-th criterion.

\begin{tabular}{ccccc}
\hline \multirow{2}{*}{ Criteria } & $A_{1}$ & $A_{2}$ & $\ldots$ & $A_{m}$ \\
\cline { 2 - 5 } & $\left\langle\left(\mu_{11}, v_{11}, r_{11}\right)\right\rangle$ & $\left\langle\left(\mu_{12}, v_{12 k}, r_{12}\right)\right\rangle$ & $\ldots$ & $\left\langle\left(\mu_{1 m}, v_{1 m}, r_{2 m}\right)\right\rangle$ \\
\hline$C_{1}$ & $\vdots$ & $\vdots$ & $\ddots$ & $\vdots$ \\
$C_{2}$ & $\left\langle\left(\mu_{21}, v_{21}, r_{21}\right)\right\rangle$ & $\left\langle\left(\mu_{22 k}, v_{22}, r_{22}\right)\right\rangle$ & $\ldots$ & $\left\langle\left(\mu_{2 m}, v_{2 m}, r_{2 m}\right)\right\rangle$ \\
$\vdots$ & $\vdots$ & $\vdots$ & $\ldots$ & $\left\langle\left(\mu_{n m}, v_{n m}, r_{n m}\right)\right\rangle$ \\
$C_{n}$ & $\left\langle\left(\mu_{n 1}, v_{n 1}, r_{n 1}\right)\right\rangle$ & $\left\langle\left(\mu_{n 2}, v_{n 2}, r_{n 2}\right)\right\rangle$ & $\ldots$ & \\
\hline
\end{tabular}

Table 4. Circular intuitionistic fuzzy decision matrix

Step 6. Calculate the optimistic decision matrix $\left(Q^{O_{d}}=\left(q_{i j}^{O_{d}}\right)_{m \times n}\right)$ and the pessimistic decision matrix $\left(\mathcal{Q}^{P_{d}}=\left(q_{i j}^{P_{d}}\right)_{m \times n}\right)$ using Eqs. (26) and (27), respectively. The conversion from the circular intuitionistic fuzzy decision matrix into the intuitionistic fuzzy decision matrix is performed by utilizing the membership functions and radius given in Table 4. Here, according to the attitude of the decision-maker to be optimistic or pessimistic, two different decision matrices are obtained, namely the optimistic decision matrix and the pessimistic decision matrix, respectively.

$\mathcal{Q}^{o_{d}=}=\begin{gathered}C_{1} \\ C_{2} \\ \vdots \\ C_{n}\end{gathered}\left[\begin{array}{cccc}\left\langle\left(\mu_{11}+r_{11}, v_{11}-r_{11}\right)\right\rangle & \left\langle\left(\mu_{12}+r_{12}, v_{12 k}-r_{12}\right)\right\rangle & \cdots & \left\langle\left(\mu_{1 m}+r_{2 m}, v_{1 m}-r_{2 m}\right)\right\rangle \\ \left\langle\left(\mu_{21}+r_{21}, v_{21}-r_{21}\right)\right\rangle & \left\langle\left(\mu_{22 k}+r_{22}, v_{22}-r_{22}\right)\right\rangle & \cdots & \left\langle\left(\mu_{2 m}+r_{2 m}, v_{2 m}-r_{2 m}\right)\right\rangle \\ \vdots & \vdots & \ddots & \vdots \\ \left\langle\left(\mu_{n 1}+r_{n 1}, v_{n 1}-r_{n 1}\right)\right\rangle & \left\langle\left(\mu_{n 2}+r_{22}, v_{n 2}-r_{n 2}\right)\right\rangle & \cdots & \left\langle\left(\mu_{n m}+r_{n m}, v_{n m}-r_{n m}\right)\right\rangle\end{array}\right]$

where $q_{i j}^{o_{d}}=\left\langle\left(\mu_{i j}+r_{i j}, v_{i j}-r_{i j}\right)\right\rangle$, 
$\mathcal{Q}^{P_{d}=} \begin{gathered}C_{1} \\ C_{2} \\ \vdots \\ C_{n}\end{gathered}\left[\begin{array}{cccc}\left\langle\left(\mu_{11}-r_{11}, v_{11}+r_{11}\right)\right\rangle & \left\langle\left(\mu_{12}-r_{12}, v_{12 k}+r_{12}\right)\right\rangle & \cdots & \left\langle\left(\mu_{1 m}-r_{2 m}, v_{1 m}+r_{2 m}\right)\right\rangle \\ \left\langle\left(\mu_{21}-r_{21}, v_{21}+r_{21}\right)\right\rangle & \left\langle\left(\mu_{22 k}-r_{22}, v_{22}+r_{22}\right)\right\rangle & \cdots & \left\langle\left(\mu_{2 m}-r_{2 m}, v_{2 m}+r_{2 m}\right)\right\rangle \\ \vdots & \vdots & \ddots & \vdots \\ \left\langle\left(\mu_{n 1}-r_{n 1}, v_{n 1}+r_{n 1}\right)\right\rangle & \left\langle\left(\mu_{n 2}-r_{22}, v_{n 2}+r_{n 2}\right)\right\rangle & \cdots & \left\langle\left(\mu_{n m}-r_{n m}, v_{n m}+r_{n m}\right)\right\rangle\end{array}\right]$

where $q_{i j}^{P_{d}}=\left\langle\left(\mu_{i j}-r_{i j}, v_{i j}+r_{i j}\right)\right\rangle$.

Step 7. Determine the weights consisting of intuitionistic fuzzy pairs of criteria for each DM $\left(W_{k}\right)$ using the scale given in Table 5. Here, $W_{k}=\left(w_{j k}\right)_{1 \times n}$ indicates intuitionistic fuzzy pairs of the $k$-th DM with respect to the $j$-th criterion.

\begin{tabular}{lcc}
\hline \multirow{2}{*}{ Linguistic terms } & \multicolumn{2}{c}{ IFNs for criteria } \\
\cline { 2 - 3 } & $\boldsymbol{m}$ & $\boldsymbol{n}$ \\
\hline Certainly High Importance - (CHI) & 0.9 & 0.1 \\
Very High Importance - (VHI) & 0.8 & 0.15 \\
High Importance - (HI) & 0.7 & 0.25 \\
Above Average Importance - (AAI) & 0.6 & 0.35 \\
Average Importance - (AI) & 0.5 & 0.45 \\
Under Average Importance - (UAI) & 0.4 & 0.55 \\
Low Importance - (LI) & 0.3 & 0.65 \\
Very Low Importance - (VLI) & 0.2 & 0.75 \\
Certainly Low Importance - (CLI) & 0.1 & 0.9 \\
\hline
\end{tabular}

Table 5. Linguistic scale for weighting the criteria

Step 8. Obtain the aggregated intuitionistic fuzzy criteria weight matrix using the individual criteria weight matrices consisting of intuitionistic fuzzy pairs. The intuitionistic fuzzy pairs in the individual criteria weight matrices are converted to the aggregated intuitionistic fuzzy numbers of criteria weights using the IFWG operator given in Definition 2.4.

Step 9. Calculate the maximum radius lengths $R^{W}=\left(r_{j}^{w}\right)_{1 \times n}$ based on the criterion weight matrices of all DMs using Eq. (14). The maximum radius lengths are found by considering the radius lengths obtained by each DM with respect to the $j$-th criterion. Then, the circular intuitionistic fuzzy criteria weight matrix $(W)$ is constructed as in Table 6. Here, $W=\left(w_{j}\right)_{1 \times n}$ in which $w_{j}=\left(\mu_{j}, v_{j}, r_{j}\right)$ indicates the circular intuitionistic fuzzy weight of the $j$-th criterion.

\begin{tabular}{cc}
\hline Criterion & Circular intuitionistic fuzzy criteria weights \\
\hline$C_{1}$ & $\left(\mu_{1}, v_{1}, r_{1}\right)$ \\
$C_{2}$ & $\left(\mu_{2}, v_{2}, r_{2}\right)$ \\
$\vdots$ & $\vdots$ \\
$C_{n}$ & $\left(\mu_{n}, v_{n}, r_{n}\right)$ \\
\hline
\end{tabular}

Table 6. Circular intuitionistic fuzzy criterion weight matrix

Step 10. Calculate the optimistic criterion weight matrix $\left(Q^{O_{w}}=\left(q_{j}^{O_{w}}\right)_{n \times 1}\right)$ and the pessimistic 
criterion weight matrix $\left(\mathcal{Q}^{P_{w}}=\left(q_{j}^{P_{w}}\right)_{n \times 1}\right)$ using Eqs. (28) and (29), respectively. The conversion of the circular intuitionistic fuzzy criterion weight matrix into the intuitionistic fuzzy criterion weight matrix is performed by utilizing the membership functions and radius given in Table 6. Here, according to the attitude of the decisionmaker to be optimistic and pessimistic, two different criteria weight matrices are obtained, namely the optimistic criterion weight matrix and the pessimistic criterion weight matrix, respectively.

$$
\left.\left.\left.\begin{array}{rl}
\mathcal{Q}^{O_{w}}= & \left.\begin{array}{c}
C_{1} \\
C_{2} \\
\vdots
\end{array}\left[\begin{array}{c}
\left\langle\left(\mu_{1}+r_{1}, v_{1}-r_{1}\right)\right\rangle \\
\left.C_{n}\left[r_{2}, v_{2}-r_{2}\right)\right\rangle \\
\vdots
\end{array}\right] \quad \text { where } q_{j}^{O_{w}}=\left\langle\left(\mu_{n}+r_{n}, v_{n}-r_{n}\right)\right\rangle\right]
\end{array}\right] \quad v_{j}-r_{j}\right)\right\rangle,
$$

Step 11. Obtain the weighted optimistic decision matrix $\left(\Psi^{O}=\left(\psi_{i j}^{O}\right)\right)$ and the weighted pessimistic decision matrix $\left(\Psi^{P}=\left(\psi_{i j}^{P}\right)\right)$ using Eqs. (30) and (31), respectively. Here, the decision matrices obtained in Step 6 and the weight vectors obtained in Step 10 are used.

$$
\begin{aligned}
& \psi_{i j}^{O}=q_{j}^{O_{w}} \otimes q_{i j}^{O_{d}}, \\
& \tilde{\psi}_{i j}^{P}=q_{j}^{P_{w}} \otimes q_{i j}^{P_{d}} .
\end{aligned}
$$

Step 12. Determine the positive ideal solution $\chi_{O}^{*}$ and negative ideal solution $\chi_{O}^{-}$based on the optimistic matrix and positive ideal solution $\chi_{P}^{*}$ and negative ideal solution $\chi_{P}^{-}$based on the pessimistic matrix by using score function and accuracy function given in Eqs. (6) and (7), respectively.

The positive ideal solution and negative ideal solution based on the optimistic matrix are as in Eqs. (32) and (33), respectively.

$$
\begin{aligned}
& x^{O^{*}}=\left\{\left\langle\left(\max _{i} \psi_{i j}^{O} \mid j \in \mathcal{J}_{1}\right),\left(\min _{i} \psi_{i j}^{O} \mid j \in \mathcal{J}_{2}\right)\right\rangle \mid j=1,2, \ldots, n\right\}^{T}=\left\{\psi_{1}^{O^{+}}, \psi_{2}^{O^{+}}, \ldots, \psi_{n}^{O^{+}}\right\}^{T}, \\
& x^{O^{-}}=\left\{\left\langle\left(\min _{i} \psi_{i j}^{O} \mid j \in \mathcal{J}_{1}\right),\left(\max _{i} \psi_{i j}^{O} \mid j \in \mathcal{J}_{2}\right)\right\rangle \mid j=1,2, \ldots, n\right\}^{T}=\left\{\psi_{1}^{O^{-}}, \psi_{2}^{O^{-}}, \ldots, \psi_{n}^{O^{-}}\right\}^{T} .
\end{aligned}
$$

The positive ideal solution and negative ideal solution based on pessimistic matrix are as in Eqs. (34) and (35), respectively.

$$
\begin{aligned}
& x^{P^{*}}=\left\{\left\langle\left(\max _{i} \psi_{i j}^{P} \mid j \in \mathcal{J}_{1}\right),\left(\min _{i} \psi_{i j}^{P} \mid j \in \mathcal{J}_{2}\right)\right\rangle \mid j=1,2, \ldots, n\right\}^{T}=\left\{\psi_{1}^{P^{+}}, \psi_{2}^{P^{+}}, \ldots, \psi_{n}^{P^{+}}\right\}^{T}, \\
& x^{P^{-}}=\left\{\left\langle\left(\min _{i} \psi_{i j}^{P} \mid j \in \mathcal{J}_{1}\right),\left(\max _{i} \psi_{i j}^{P} \mid j \in \mathcal{J}_{2}\right)\right\rangle \mid j=1,2, \ldots, n\right\}^{T}=\left\{\psi_{1}^{P^{-}}, \psi_{2}^{P^{-}}, \ldots, \psi_{n}^{P^{-}}\right\}^{T},
\end{aligned}
$$
where $\psi_{j}^{O^{+}}=\left(\mu_{j}^{O^{+}}, v_{j}^{O^{+}}\right), \psi_{j}^{P^{+}}=\left(\mu_{j}^{P^{+}}, v_{j}^{P^{+}}\right)$are the maximum IFN with the highest score value among alternatives for the $j$-th criterion and $\psi_{j}^{O^{-}}=\left(\mu_{j}^{O^{-}}, v_{j}^{O^{-}}\right), \psi_{j}^{P^{-}}=$ 
$\left(\mu_{j}^{P^{-}}, v_{j}^{P^{-}}\right)$are the minimum IFN with the lowest score value among alternatives for the $j$-th criterion. Also, $\mathcal{J}_{1}, \mathcal{J}_{2}$ are benefit and cost criteria, respectively and $j=1,2, \ldots, n$.

Step 13. Obtain the separation measures by calculating the distances for each alternative according to the positive-ideal solutions $\left(X^{O^{*}}\right),\left(\chi^{P^{*}}\right)$ and negative-ideal solutions $\left(X^{O^{-}}\right),\left(X^{P^{-}}\right)$.

The distances to the positive ideal solution and negative ideal solution based on the optimistic matrix are given by Eqs. (36) and (37), respectively.

$$
\begin{gathered}
\mathcal{D}_{i}^{O^{*}}=\left(\frac{1}{2 n} \sum_{j=1}^{n}\left(\left|\mu_{i j}-\mu_{j}^{O^{+}}\right|^{2}+\left|v_{i j}-v_{j}^{O^{+}}\right|^{2}+\left|\pi_{i j}-\pi_{j}^{O^{+}}\right|^{2}\right)\right)^{1 / 2} . \\
\mathcal{D}_{i}^{O^{-}}=\left(\frac{1}{2 n} \sum_{j=1}^{n}\left(\left|\mu_{i j}-\mu_{j}^{O^{-}}\right|^{2}+\left|v_{i j}-v_{j}^{O^{-}}\right|^{2}+\left|\pi_{i j}-\pi_{j}^{O^{-}}\right|^{2}\right)\right)^{1 / 2} .
\end{gathered}
$$

The distances to positive ideal solution and negative ideal solution based on the pessimistic matrix are given by Eqs. (38) and (39), respectively.

$$
\begin{aligned}
& \mathcal{D}_{i}^{P^{*}}=\left(\frac{1}{2 n} \sum_{j=1}^{n}\left(\left|\mu_{i j}-\mu_{j}^{P^{+}}\right|^{2}+\left|v_{i j}-v_{j}^{P^{+}}\right|^{2}+\left|\pi_{i j}-\pi_{j}^{P^{+}}\right|^{2}\right)\right)^{1 / 2} . \\
& \mathcal{D}_{i}^{P^{-}}=\left(\frac{1}{2 n} \sum_{j=1}^{n}\left(\left|\mu_{i j}-\mu_{j}^{P^{-}}\right|^{2}+\left|v_{i j}-v_{j}^{P^{-}}\right|^{2}+\left|\pi_{i j}-\pi_{j}^{P^{-}}\right|^{2}\right)\right)^{1 / 2} .
\end{aligned}
$$

Step 14. Calculate the relative closeness coefficient based on the optimistic matrix $\left(C C_{i}^{O}\right)$ and the relative closeness coefficient based on the pessimistic matrix $\left(C C_{i}^{P}\right)$ of alternatives using Eqs. (40) and (41), respectively.

$$
\begin{aligned}
C C_{i}^{O} & =\frac{\mathcal{D}_{i}^{O^{-}}}{\mathcal{D}_{i}^{O^{-}}+\mathcal{D}_{i}^{O^{*}}} . \\
C C_{i}^{P} & =\frac{\mathcal{D}_{i}^{P^{-}}}{\mathcal{D}_{i}^{P^{-}}+\mathcal{D}_{i}^{P^{*}}} .
\end{aligned}
$$

Step 15. Obtain the composite ratio $(C R)$ score to determine the rankings between alternatives considering the scores obtained with both the optimistic approach and the pessimistic approach as given in Eq. (42).

$$
C C_{i}^{C R}=\lambda \times C C_{i}^{O}+(1-\lambda) \times C C_{i}^{P},
$$

where $\lambda$ is the weight of DM's optimistic attitude and $(1-\lambda)$ is the weight of DM's pessimistic attitude.

Step 16. Rank the alternatives according to final scores. The best alternative(s) are selected based on the descending order of the values of the relative closeness coefficient $\left(C C_{i}^{C R}\right)$.

\section{Application to a supplier selection problem}

MCDM methods can be successfully used in determining the most appropriate supplier selection. Therefore, in this section, the selection of suitable suppliers in fast-moving consumer goods is 
evaluated by using the suggested approach and it is aimed to select the best supplier among several alternatives.

To evaluate supplier alternatives, a variety of criteria have been determined as defined in Sub-section 2.2 based on a comprehensive literature review and experts' opinions. As potential fast-moving consumer goods (FMCG) suppliers in this study, A1, A2, A3, and A4 are evaluated according to the determined seven criteria. The hierarchical structure of the problem is given in Fig. 8.

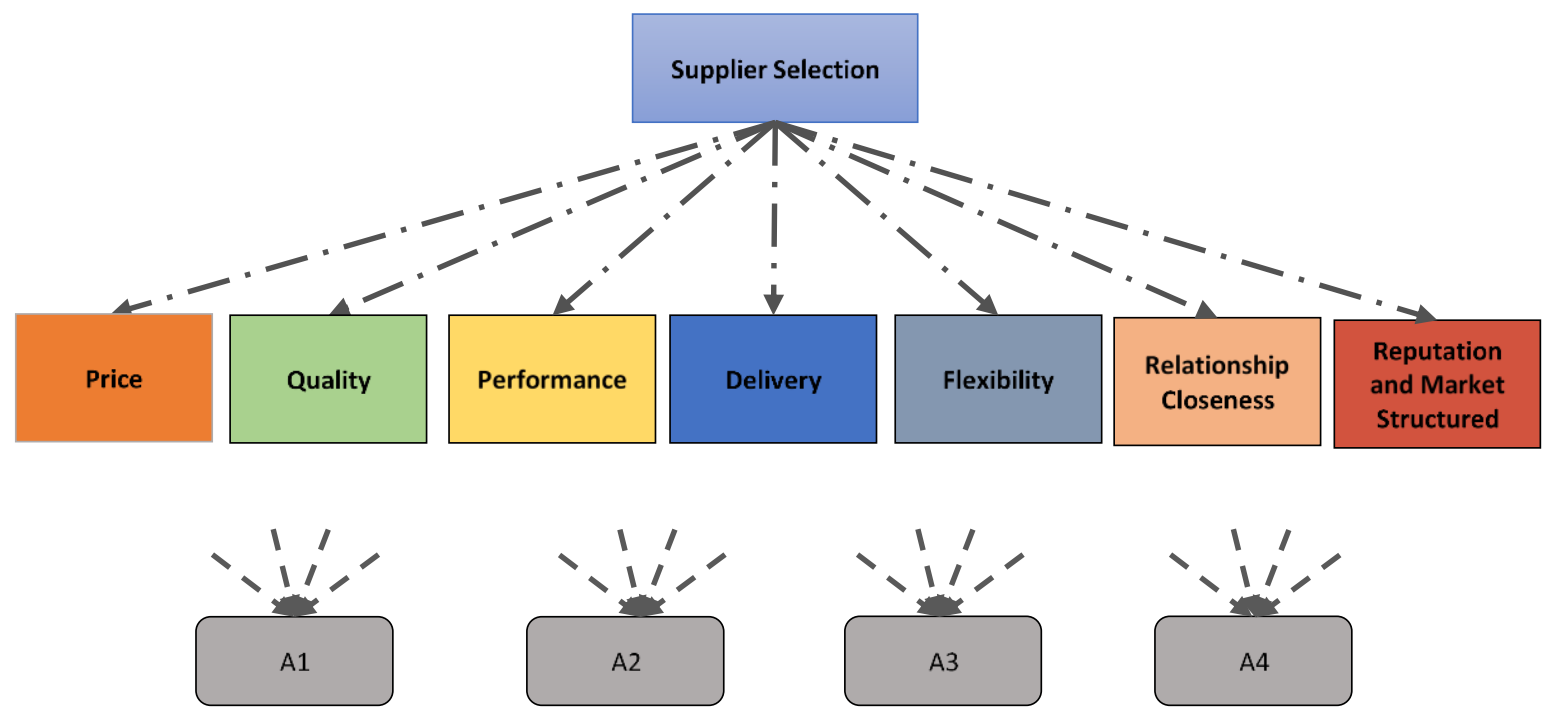

Figure 8. Hierarchical structure of the problem

\subsection{CIF-TOPSIS application}

The solutions of the defined problem through the proposed circular intuitionistic TOPSIS method have been presented in the following algorithm.

Step 1. The proposed approach is applied to the most appropriate supplier selection among four alternatives in FMCG. These alternatives (A1, A2, A3, and A4) are evaluated according to seven criteria determined based on comprehensive literature review and expert opinions. A team of experts has been formed to evaluate the suppliers using the proposed approach. Five decision-makers have been selected, consisting of supplier experts and expert academics on multi-criteria decision making in a fuzzy environment and have been abbreviated as DM1, DM2, DM3, DM4 and DM5, respectively.

Step 2. The decision-makers evaluate suppliers in line with the defined objectives and criteria based on the intuitionistic fuzzy linguistic scale given in Table 1. The linguistic decision matrix created based on the assessments of experts is presented in Table 7.

Steps 3 and 4. Linguistic variables are converted to their corresponding IFNs by utilizing the scale given in Table 2. Then, the individual decision matrices consisting of intuitionistic fuzzy pairs are combined to obtain the aggregated intuitionistic fuzzy decision matrix as in Table 8 using Eq. (13). 


\begin{tabular}{llllll}
\hline Criteria & DMs & A1 & A2 & A3 & A4 \\
\hline \multirow{4}{*}{ C1 } & DM1 & AAV & UAV & HV & LV \\
& DM2 & HV & LV & VHV & VLV \\
& DM3 & HV & UAV & AAV & LV \\
& DM4 & AAV & AV & AAV & LV \\
& DM5 & AV & UAV & HV & VLV \\
C2 & DM1 & AV & AAV & VHV & LV \\
& DM2 & AAV & AV & HV & UAV \\
& DM3 & UAV & HV & AAV & UAV \\
& DM4 & AV & AAV & AV & AV \\
& DM5 & UAV & AV & AAV & AV \\
C3 & DM1 & AV & HV & AV & LV \\
& DM2 & AAV & AV & AV & UAV \\
& DM3 & AAV & AV & AAV & UAV \\
& DM4 & UAV & AAV & AAV & AV \\
& DM5 & AV & AAV & AV & AV \\
C4 & DM1 & HV & LV & VHV & AV \\
& DM2 & HV & VLV & VHV & AV \\
& DM3 & AAV & VLV & HV & AAV \\
& DM4 & AV & LV & HV & UAV \\
& DM5 & AV & LV & AAV & AV \\
& DM1 & LV & AV & AV & UAV \\
C5 & DM2 & UAV & AV & AV & UAV \\
& DM3 & UAV & UAV & AAV & AV \\
& DM4 & AV & AAV & AAV & AAV \\
& DM5 & LV & AAV & AV & AV \\
& DM1 & HV & AAV & AAV & AAV \\
& DM2 & HV & AAV & HV & AAV \\
C6 & DM3 & VHV & AV & HV & AV \\
& DM4 & HV & AV & AAV & AAV \\
& DM5 & AAV & AAV & HV & AAV \\
& DM1 & AV & AV & HV & VHV \\
& DM2 & UAV & AV & HV & VHV \\
& DM3 & UAV & AAV & VHV & HV \\
& DM4 & AV & HV & AAV & HV \\
& DM5 & AV & HV & HV & HV \\
\hline \multirow{4}{*}{} & & & & & \\
& & & & & \\
& & & & &
\end{tabular}

Table 7. Linguistic decision matrix for each expert

\begin{tabular}{lllll}
\hline & \multicolumn{1}{c}{$\mathbf{A 1}$} & \multicolumn{1}{c}{$\mathbf{A 2}$} & \multicolumn{1}{c}{$\mathbf{A 3}$} & \multicolumn{1}{c}{$\mathbf{A 4}$} \\
\hline C1 & $(0.62,0.33)$ & $(0.4,0.55)$ & $(0,68,0.27)$ & $(0.26,0.69)$ \\
C2 & $(0.48,0.47)$ & $(0.58,0.37)$ & $(0.64,0.31)$ & $(0.42,0.53)$ \\
C3 & $(0.52,0.43)$ & $(0,58,0.37)$ & $(0,54,0.41)$ & $(0.42,0.53)$ \\
C4 & $(0.6,0.35)$ & $(0.26,0.69)$ & $(0.72,0.23)$ & $(0.5,0.45)$ \\
C5 & $(0.38,0.57)$ & $(0.52,0.43)$ & $(0.54,0.41)$ & $(0,48,0,47)$ \\
C6 & $(0.7,0.25)$ & $(0.56,0.39)$ & $(0,66,0.29)$ & $(0.58,0.37)$ \\
C7 & $(0.46,0.49)$ & $(0.6,0.35)$ & $(0.7,0.25)$ & $(0.74,0.21)$ \\
\hline
\end{tabular}

Table 8. Aggregated intuitionistic fuzzy decision matrix

Step 5. After the radius lengths based on decision matrices of each expert are calculated, the maximum radius among all experts is obtained as seen in Table 9 using Eq. (14). Then, the circular intuitionistic fuzzy decision matrix is constructed as in Table 10 by utilizing the radius lengths obtained. 


\begin{tabular}{lcccc}
\hline & A1 & A2 & A3 & A4 \\
\hline C1 & 0.169 & 0.14 & 0.169 & 0.085 \\
C2 & 0.169 & 0.169 & 0.226 & 0.169 \\
C3 & 0.169 & 0.169 & 0.085 & 0.169 \\
C4 & 0.14 & 0.085 & 0.169 & 0.141 \\
C5 & 0.169 & 0.169 & 0.085 & 0.169 \\
C6 & 0.14 & 0.085 & 0.085 & 0.113 \\
C7 & 0.08 & 0.141 & 0.141 & 0.085 \\
\hline
\end{tabular}

Table 9. Maximum radius lengths based on decision matrices

Step 6. By utilizing the circular intuitionistic fuzzy decision matrix based on the membership functions and radius lengths obtained in Step 5 using Eqs. (26) and (27), the optimistic and pessimistic decision matrices are created as in Tables 11 and 12.

\begin{tabular}{lllll}
\hline & \multicolumn{1}{c}{ A1 } & \multicolumn{1}{c}{ A2 } & \multicolumn{1}{c}{ A3 } & \multicolumn{1}{c}{ A4 } \\
\hline C1 & $\langle((0.62,0.33) ; 0.169\rangle$ & $\langle(0.4,0.55) ; 0.14\rangle$ & $\langle(0,68,0.27) ; 0.169\rangle$ & $\langle(0.26,0.69) ; 0.085\rangle$ \\
C2 & $\langle(0.48,0.47) ; 0.169\rangle$ & $\langle(0.58,0.37) ; 0.169\rangle$ & $\langle(0.64,0.31) ; 0.226\rangle$ & $\langle(0.42,0.53) ; 0.169\rangle$ \\
C3 & $\langle(0.52,0.43) ; 0.169\rangle$ & $\langle(0,58,0.37) ; 0.169\rangle$ & $\langle(0,54,0.41) ; 0.085\rangle$ & $\langle(0.42,0.53) ; 0.169\rangle$ \\
C4 & $\langle(0.6,0.35) ; 0.14\rangle$ & $\langle(0.26,0.69) ; 0.085\rangle$ & $\langle(0.72,0.23) ; 0.169\rangle$ & $\langle(0.5,0.45) ; 0.141\rangle$ \\
C5 & $\langle(0.38,0.57) ; 0.169\rangle$ & $\langle(0.52,0.43) ; 0.169\rangle$ & $\langle(0.54,0.41) ; 0.085\rangle$ & $\langle(0,48,0,47) ; 0.169\rangle$ \\
C6 & $\langle(0.7,0.25) ; 0.14\rangle$ & $\langle(0.56,0.39) ; 0.085\rangle$ & $\langle(0,66,0.29) ; 0.085\rangle$ & $\langle(0.58,0.37) ; 0.113\rangle$ \\
C7 & $\langle(0.46,0.49) ; 0.08\rangle$ & $\langle(0.6,0.35) ; 0.141\rangle$ & $\langle(0.7,0.25) ; 0.141\rangle$ & $\langle(0.74,0.21) ; 0.085\rangle$ \\
\hline
\end{tabular}

Table 10. Circular intuitionistic fuzzy decision matrix

\begin{tabular}{ccccc}
\hline & A1 & A2 & A3 & A4 \\
\hline C1 & $(0.790,0.160)$ & $(0.541,0.409)$ & $(0.850,0.100)$ & $(0.345,0.605)$ \\
C2 & $(0.650,0.300)$ & $(0.750,0.200)$ & $(0.866,0.084)$ & $(0.590,0.360)$ \\
C3 & $(0.690,0.260)$ & $(0,750,0.200)$ & $(0.625,0.325)$ & $(0.590,0.360)$ \\
C4 & $(0.741,0.209)$ & $(0.345,0.605)$ & $(0.890,0.060)$ & $(0.641,0.309)$ \\
C5 & $(0.550,0.400)$ & $(0.690,0.260)$ & $(0.625,0.325)$ & $(0.649,0.300)$ \\
C6 & $(0.841,0.109)$ & $(0.645,0.305)$ & $(0.744,0.205)$ & $(0.693,0.257)$ \\
C7 & $(0.545,0.405)$ & $(0.741,0.209)$ & $(0.841,0.109)$ & $(0.825,0.125)$ \\
\hline
\end{tabular}

Table 11. Optimistic decision matrix

\begin{tabular}{ccccc}
\hline & A1 & A2 & A3 & A4 \\
\hline C1 & $(0.450,0.500)$ & $(0.259,0.691)$ & $(0.510,0.440)$ & $(0.175,0.775)$ \\
C2 & $(0.310,0.640)$ & $(0.410,0.540)$ & $(0.414,0.536)$ & $(0.250,0.700)$ \\
C3 & $(0.350,0.600)$ & $(0,410,0.540)$ & $(0.455,0.495)$ & $(0.250,0.700)$ \\
C4 & $(0.459,0.491)$ & $(0.175,0.775)$ & $(0.550,0.400)$ & $(0.359,0.591)$ \\
C5 & $(0.210,0.740)$ & $(0.350,0.600)$ & $(0.455,0.495)$ & $(0.310,0.640)$ \\
C6 & $(0.559,0.391)$ & $(0.475,0.475)$ & $(0.575,0.375)$ & $(0.467,0.483)$ \\
C7 & $(0.375,0.575)$ & $(0.459,0.491)$ & $(0.559,0.391)$ & $(0.655,0.295)$ \\
\hline
\end{tabular}

Table 12. Pessimistic decision matrix 
Steps 7 and 8. The linguistic evaluations of the criteria assigned by DMs using the scale given in Table 5 and the aggregated intuitionistic fuzzy criteria weights obtained by using their weights consisting of intuitionistic fuzzy pairs are indicated in Table 13.

Steps 9 and 10. After the maximum radius length among all experts is obtained based on the radius lengths calculated for each expert using Eq. (14), the circular intuitionistic fuzzy criteria weight matrix is constructed as in Table 14 by utilizing the maximum radius lengths obtained.

\begin{tabular}{llllllllc}
\hline \multirow{2}{*}{ Criterion } & \multirow{2}{*}{ DM1 } & \multirow{2}{*}{ DM2 } & \multirow{2}{*}{ DM3 } & \multirow{2}{*}{ DM4 } & \multirow{2}{*}{ DM5 } & \multirow{2}{*}{ Aggregated Weights } & \multicolumn{2}{c}{ Type } \\
\hline C1 & AAI & AI & AI & AAI & AI & $(0.537,0.412)$ & $\checkmark$ & Benefit \\
C2 & VHI & CHI & CHI & VHI & CHI & $(0.859,0.120)$ & & $\checkmark$ \\
C3 & HI & VHI & HI & HI & VHI & $(0.738,0.211)$ & & $\checkmark$ \\
C4 & VHI & VHI & HI & HI & VHI & $(0.758,0.192)$ & & $\checkmark$ \\
C5 & HI & HI & VHI & VHI & HI & $(0.738,0.211)$ & $\checkmark$ \\
C6 & AAI & HI & AAI & AI & HI & $(0.615,0.334)$ & $\checkmark$ \\
C7 & AAI & AAI & AI & AAI & AI & $(0.558,0.392)$ & $\checkmark$ \\
\hline
\end{tabular}

Table 13. Linguistic evaluations of criteria for each DM and aggregated criterion weights

\begin{tabular}{lcl}
\hline & Maximum Radius & Criteria weight matrix \\
\hline C1 & 0.088 & $\langle(0.537,0.412) ; 0.088\rangle$ \\
C2 & 0.066 & $\langle(0.859,0.120) ; 0.066\rangle$ \\
C3 & 0.087 & $\langle(0.738,0.211) ; 0.087\rangle$ \\
C4 & 0.083 & $\langle(0.758,0.192) ; 0.083\rangle$ \\
C5 & 0.087 & $\langle(0.738,0.211) ; 0.087\rangle$ \\
C6 & 0.163 & $\langle(0.615,0.334), 0.163\rangle$ \\
C7 & 0.082 & $\langle(0.558,0.392) ; 0.082\rangle$ \\
\hline
\end{tabular}

Table 14. Maximum radius lengths based on decision matrices and circular intuitionistic fuzzy criteria weight matrix

Step 11. By utilizing the circular intuitionistic fuzzy criterion weight matrix based on the membership functions and radius lengths obtained in Step 9, the optimistic and pessimistic criteria weight matrices are constructed as in Table 15 using Eqs. (28) and (29), respectively.

\begin{tabular}{lcc}
\hline & Optimistic criteria weights & Pessimistic criteria weights \\
\hline C1 & $(0.626,0.324)$ & $(0.450,0.500)$ \\
C2 & $(0.924,0.055)$ & $(0.793,0.186)$ \\
C3 & $(0.825,0.124)$ & $(0.651,0.299)$ \\
C4 & $(0.841,0.109)$ & $(0.676,0.274)$ \\
C5 & $(0.825,0.124)$ & $(0.651,0.299)$ \\
C6 & $(0.779,0.171)$ & $(0.452,0.498)$ \\
C7 & $(0.640,0.310)$ & $(0.476,0.474)$ \\
\hline
\end{tabular}

Table 15. Optimistic and pessimistic criteria weight matrices 
Step 12. The weighted optimistic and pessimistic decision matrices are created based on the decision matrices obtained in Step 7 and the weight vectors obtained in Step 11 by utilizing Eqs. (30) and (31), respectively. The weighted optimistic and pessimistic decision matrices are as in Tables 16 and 17.

\begin{tabular}{ccccc}
\hline & A1 & A2 & A3 & A4 \\
\hline C1 & {$[0.494,0.433]$} & {$[0.339,0.600]$} & {$[0.532,0.392]$} & {$[0.216,0.733]$} \\
C2 & {$[0.600,0.339]$} & {$[0.693,0.244]$} & {$[0.801,0.134]$} & {$[0.545,0.395]$} \\
C3 & {$[0.569,0.352]$} & {$[0,619,0.300]$} & {$[0.516,0.409]$} & {$[0.487,0.440]$} \\
C4 & {$[0.624,0.295]$} & {$[0.290,0.648]$} & {$[0.748,0.163]$} & {$[0.539,0.383]$} \\
C5 & {$[0.454,0.475]$} & {$[0.569,0.352]$} & {$[0.516,0.409]$} & {$[0.536,0.387]$} \\
C6 & {$[0.655,0.261]$} & {$[0.502,0.424]$} & {$[0.580,0.341]$} & {$[0.540,0.384]$} \\
C7 & {$[0.349,0.590]$} & {$[0.474,0.454]$} & {$[0.538,0.385]$} & {$[0.528,0.396]$} \\
\hline
\end{tabular}

Table 16. Weighted optimistic decision matrix

\begin{tabular}{ccccc}
\hline & A1 & A2 & A3 & A4 \\
\hline C1 & {$[0.203,0.750]$} & {$[0.116,0.846]$} & {$[0.230,0.761]$} & {$[0.079,0.887]$} \\
C2 & {$[0.026,0.709]$} & {$[0.325,0.625]$} & {$[0.328,0.623]$} & {$[0.198,0.756]$} \\
C3 & {$[0.020,0.611]$} & {$[0,267,0.677]$} & {$[0.296,0.646]$} & {$[0.163,0.789]$} \\
C4 & {$[0.039,0.506]$} & {$[0.118,0.837]$} & {$[0.372,0.564]$} & {$[0.242,0.703]$} \\
C5 & {$[0.012,0.747]$} & {$[0.228,0.719]$} & {$[0.296,0.646]$} & {$[0.202,0.747]$} \\
C6 & {$[0.032,0.460]$} & {$[0.215,0.736]$} & {$[0.260,0.686]$} & {$[0.211,0.740]$} \\
C7 & {$[0.032,0.587]$} & {$[0.218,0.732]$} & {$[0.266,0.680]$} & {$[0.312,0.629]$} \\
\hline
\end{tabular}

Table 17. Weighted pessimistic decision matrix

Step 13. After score values for each IFN in the weighted optimistic and pessimistic decision matrices are calculated using Eq. (6), while the positive and negative ideal solutions based on the optimistic decision matrix are obtained by using Eqs. (32) and (33), the positive and negative ideal solutions based on the pessimistic decision matrix are found by using Eqs. (34) and (35). The obtained positive and negative ideal solutions are as in Table 18.

\begin{tabular}{llllll}
\hline & \multicolumn{2}{c}{ Optimistic matrix } & & \multicolumn{2}{c}{ Pessimistic matrix } \\
\cline { 2 - 3 } \cline { 5 - 6 } & Positive ideal solution & Negative ideal solution & & Positive ideal solution & Negative ideal solution \\
\hline C1 & {$[0.216,0.733]$} & {$[0.532,0.392]$} & & {$[0.079,0.887]$} & {$[0.230,0.720]$} \\
C2 & {$[0.801,0.134]$} & {$[0.545,0.395]$} & & {$[0.328,0.623]$} & {$[0.026,0.701]$} \\
C3 & {$[0.619,0.300]$} & {$[0,487,0.440]$} & & {$[0.296,0.646]$} & {$[0.163,0.789]$} \\
C4 & {$[0.748,0.163]$} & {$[0.290,0.648]$} & & {$[0.372,0.564]$} & {$[0.118,0.837]$} \\
C5 & {$[0.569,0.352]$} & {$[0.454,0.475]$} & & {$[0.296,0.646]$} & {$[0.012,0.747]$} \\
C6 & {$[0.655,0.261]$} & {$[0.502,0.424]$} & & {$[0.260,0.686]$} & {$[0.211,0.740]$} \\
C7 & {$[0.538,0.385]$} & {$[0.349,0.590]$} & & {$[0.312,0.629]$} & {$[0.032,0.587]$} \\
\hline
\end{tabular}

Table 18. Positive and negative ideal solutions based on the optimistic decision matrix

Step 14. The separation measures are obtained by calculating the distances for each alternative according to the positive and negative ideal solutions based on optimistic and pessimistic matrices. While the separation measures based on the optimistic matrix are presented as 
in Table 19 using Eqs. (36) and (37), the separation measures based on the pessimistic matrix are created as in Table 20 using Eqs. (38) and (39).

\begin{tabular}{cccccccc}
\hline & A1 & A2 & A3 & A4 & A5 & A6 & A7 \\
\hline $\mathcal{D}_{i}^{O^{*}}$ & 0.168 & 0.160 & 0.145 & 0.202 & 0.318 & 0.257 & 0.165 \\
$\mathcal{D}_{i}^{O^{-}}$ & 0.149 & 0.127 & 0.221 & 0.177 & 0.167 & 0.143 & 0.257 \\
\hline
\end{tabular}

Table 19. Separation measures of the alternatives based on the optimistic matrix

\begin{tabular}{cccccccc}
\hline & $\mathbf{A 1}$ & $\mathbf{A 2}$ & $\mathbf{A 3}$ & $\mathbf{A 4}$ & $\mathbf{A 5}$ & $\mathbf{A 6}$ & $\mathbf{A 7}$ \\
\hline $\mathcal{D}_{i}^{P^{*}}$ & 0.298 & 0.087 & 0.112 & 0.136 & 0.276 & 0.216 & 0.023 \\
$\mathcal{D}_{i}^{P^{-}}$ & 0.223 & 0.179 & 0.211 & 0.174 & 0.116 & 0.104 & 0.222 \\
\hline
\end{tabular}

Table 20. Separation measures of the alternatives based on the pessimistic matrix

Step 15. The closeness coefficient of each alternative is calculated for optimistic and pessimistic matrices. While the closeness coefficients of each alternative and ranks of the alternatives based on the optimistic are presented as given in Table 21 using Eq. (40), the closeness coefficient of each alternative and ranks of the alternatives based on the pessimistic are shown as given in Table 22 using Eq. (41).

\begin{tabular}{lllll}
\hline & $\mathbf{A 1}$ & $\mathbf{A 2}$ & $\mathbf{A 3}$ & $\mathbf{A 4}$ \\
\hline $\boldsymbol{C} \boldsymbol{C}_{\boldsymbol{i}}^{\boldsymbol{O}}$ & 0.470 & 0.443 & 0.604 & 0.466 \\
Rank & 2 & 4 & 1 & 3 \\
\hline
\end{tabular}

Table 21. Closeness coefficient and ranks of the alternatives based on optimistic decision matrix

\begin{tabular}{lllll}
\hline & $\mathbf{A 1}$ & $\mathbf{A 2}$ & $\mathbf{A 3}$ & $\mathbf{A 4}$ \\
\hline $\boldsymbol{C} \boldsymbol{C}_{\boldsymbol{i}}^{\boldsymbol{P}}$ & 0.439 & 0.672 & 0.654 & 0.562 \\
Rank & 4 & 1 & 2 & 3 \\
\hline
\end{tabular}

Table 22. Closeness coefficient and ranks of the alternatives based on pessimistic decision matrix

Step 16. The composite ratio $(C R)$ score of $C C_{i}^{O}$ and $C C_{i}^{P}$ is calculated to determine the rankings between alternatives by considering the scores obtained with both the optimistic approach and the pessimistic approach using Eq. (42) as given in Table 23. Here, the weights of DM's optimistic and pessimistic attitudes are considered equal.

\begin{tabular}{lllll}
\hline & $\mathbf{A 1}$ & $\mathbf{A 2}$ & $\mathbf{A 3}$ & $\mathbf{A 4}$ \\
\hline$C C_{i}^{C R}$ & 0.455 & 0.500 & 0.695 & 0.595 \\
Rank & 4 & 3 & 1 & 2 \\
\hline
\end{tabular}

Table 23. Composite ratio scores and ranks of the alternatives

Step 17. The combined ratio scores indicate that the ranking order of the alternatives are

$$
A 3>A 4>A 2>A 1
$$




\subsection{Sensitivity analysis}

In this section, sensitivity analysis is performed to measure the robustness of the results of the proposed methodology. The sensitivity analysis can be conducted to emphasize various scenarios in decision-makers' priorities on criterion weights that might alter the result of the proposed methodology. For this aim, in this analysis, we change the linguistic weights assigned by each expert to a certain criterion, from CHI to CLI, respectively, while keeping the linguistic weights of other criteria constant and then the criteria weights are re-calculated using these new weights. The alternatives are reordered with varying closeness coefficients and in total, the results are analyzed by performing 63 different scenarios. The results of ranks of alternatives are as presented in Fig. 9. When all the results are examined, it is seen that each criterion has an effect on the ranking of many alternatives and the combined ratio scores of all alternatives.

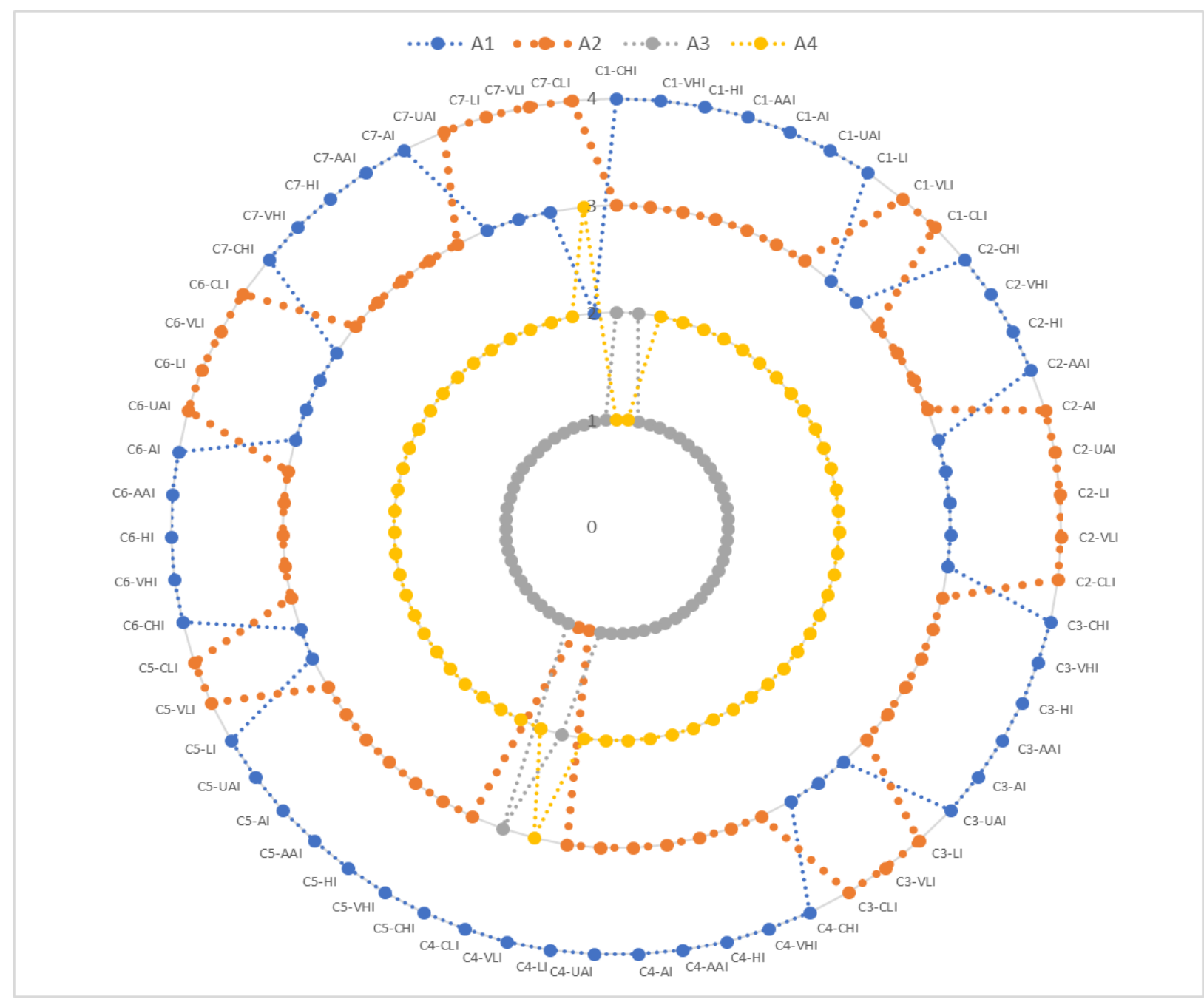

Figure 9. Sensitivity analysis based on the criteria weights

The alternative A3 is preferred over other alternatives in almost all different cases and ranks first. The ranking of the A3 alternative changes only in the CHI and CLI, which are the highest importance weights of the price criterion $(\mathrm{C} 1)$ and it is seen that it is ranked second in the ranking after the A4 alternative. When the weights of criteria quality (C3), performance (C4), delivery 
(C5), flexibility (C6), relationship closeness (C7), reputation and market structured (C8) changed from CHI to CLI, the alternative A3 preferred in the first rank as the best alternative according to others in all sensitivity analyses while the ranking of the other alternatives are seen to change. Besides, the closeness coefficients of alternatives change for each different criterion weight. The sensitivity analysis results show that the change in the weights of the criteria does not make a significant difference in the ranking of the alternatives. It is concluded that our proposed method is strong in decisions and sensitive to change in criterion weights.

\subsection{Comparative analysis}

In this subsection, we compare our proposed CIF-TOPSIS method with the intuitionistic fuzzy (IF) TOPSIS method proposed by Boran et al [8]. The scales used for CIF-TOPSIS are converted to the intuitionistic fuzzy scale developed by Boran et al. [8] for comparison purpose. In the proposed scale, we modified the linguistic terms as given in Table 24 and Table 25 and we used the same scale both in the ratings of alternatives and in the weighting of criteria for a reliable comparison.

\begin{tabular}{lc}
\hline Linguistic terms & IF number for alternatives \\
\cline { 2 - 2 } & $(\boldsymbol{\mu}, \boldsymbol{v}, \boldsymbol{\pi})$ \\
\hline Very Very High - (VVH) & $(0.9,0.1,0)$ \\
Very High - (VH) & $(0.8,0.1,0.1)$ \\
High - (H) & $(0.7,0.2,0.1)$ \\
Medium High - (MH) & $(0.6,0.3,0.1)$ \\
Medium - (M) & $(0.5,0.4,0.1)$ \\
Medium Low - (ML) & $(0.4,0.5,0.1)$ \\
Low - (L) & $(0.25,0.6,0.15)$ \\
Very Low - (VL) & $(0.2,0.75,0.15)$ \\
Very Very Low - (VVL) & $(0.1,0.9,0.1)$ \\
\hline
\end{tabular}

Table 24. Linguistic scale for ratings of alternatives

\begin{tabular}{lc}
\hline \multirow{2}{*}{ Linguistic terms } & IF number for criteria \\
\cline { 2 - 2 } & $(\boldsymbol{\mu}, \boldsymbol{v}, \boldsymbol{\pi})$ \\
\hline Certainly High Importance $-(\mathrm{CHI})$ & $(0.9,0.1,0)$ \\
Very High Importance $-(\mathrm{VHI})$ & $(0.8,0.1,0.1)$ \\
High Importance - (HI) & $(0.7,0.2,0.1)$ \\
Above Average Importance - (AAI) & $(0.6,0.3,0.1)$ \\
Average Importance - (AI) & $(0.5,0.4,0.1)$ \\
Under Average Importance - (UAI) & $(0.4,0.5,0.1)$ \\
Low Importance - (LI) & $(0.25,0.6,0.15)$ \\
Very Low Importance - (VLI) & $(0.2,0.75,0.15)$ \\
Certainly Low Importance - (CLI) & $(0.1,0.9,0.1)$ \\
\hline
\end{tabular}

Table 25. Linguistic scale for weighting the criteria

Each decision-maker assessment based on the criteria of transformed from CIF values to IF values have been presented together with the aggregated criterion weights in Table 26. Besides, the weighted aggregated decision matrix consisting of IF values are constructed as shown in Table 27. 


\begin{tabular}{ccccccl}
\hline Criterion & \multicolumn{1}{c}{ DM1 } & \multicolumn{1}{c}{ DM2 } & \multicolumn{1}{c}{ DM3 } & \multicolumn{1}{c}{ DM4 } & \multicolumn{1}{c}{ DM5 } & \multicolumn{1}{c}{ Aggregated Values } \\
\hline C1 & $(0.6,0.3,0.1)$ & $(0.5,0.4,0.1)$ & $(0.5,0.4,0.1)$ & $(0.6,0.3,0.1)$ & $(0.5,0.4,0.1)$ & $(0.357,0.543,0.101)$ \\
C2 & $(0.8,0.1,0.1)$ & $(0.9,0.1,0)$ & $(0.9,0.1,0)$ & $(0.8,0.1,0.1)$ & $(0.9,0.1,0)$ & $(0.1,0.868,0.032)$ \\
C3 & $(0.7,0.2,0.1)$ & $(0.8,0.1,0.1)$ & $(0.7,0.2,0.1)$ & $(0.7,0.2,0.1)$ & $(0.8,0.1,0.1)$ & $(0.152,0.745,0.104)$ \\
C4 & $(0.8,0.1,0.1)$ & $(0.8,0.1,0.1)$ & $(0.7,0.2,0.1)$ & $(0.7,0.2,0.1)$ & $(0.8,0.1,0.1)$ & $(0.132,0.765,0.103)$ \\
C5 & $(0.7,0.2,0.1)$ & $(0.7,0.2,0.1)$ & $(0.8,0.1,0.1)$ & $(0.8,0.1,0.1)$ & $(0.7,0.2,0.1)$ & $(0.152,0.745,0.104)$ \\
C6 & $(0.6,0.3,0.1)$ & $(0.7,0.2,0.1)$ & $(0.6,0.3,0.1)$ & $(0.5,0.4,0.1)$ & $(0.7,0.2,0.1)$ & $(0.270,0.627,0.103)$ \\
C7 & $(0.6,0.3,0.1)$ & $(0.6,0.3,0.1)$ & $(0.5,0.4,0.1)$ & $(0.6,0.3,0.1)$ & $(0.5,0.4,0.1)$ & $(0.337,0.563,0.101)$ \\
\hline
\end{tabular}

Table 26. IF values of criteria for each decision-maker and aggregated IF criterion weights

\begin{tabular}{ccccc}
\hline & A1 & A2 & A3 & A4 \\
\hline C1 & $(0.627,0.270,0.103)$ & $(0.395,0.496,0.109)$ & $(0.690,0.205,0.106)$ & $(0.193,0.656,0.151)$ \\
C2 & $(0.486,0.413,0.101)$ & $(0.587,0.310,0.103)$ & $(0.656,0.235,0.109)$ & $(0.147,0.474,0.109)$ \\
C3 & $(0.526,0.373,0.101)$ & $(0.587,0.310,0.103)$ & $(0.542,0.357,0.101)$ & $(0.417,0.474,0.109)$ \\
C4 & $(0.610,0.286,0.104)$ & $(0.193,0.656,0.151)$ & $(0.730,0.164,0.106)$ & $(0.504,0.395,0.101)$ \\
C5 & $(0.367,0.514,0.118)$ & $(0.526,0.373,0.101)$ & $(0.543,0.357,0.101)$ & $(0.485,0.413,0.101)$ \\
C6 & $(0.707,0.188,0.104)$ & $(0.563,0.337,0.101)$ & $(0.663,0.235,0.101)$ & $(0.582,0.318,0.100)$ \\
C7 & $(0.462,0.437,0.100)$ & $(0.610,0.286,0.104)$ & $(0.707,0.189,0.104)$ & $(0.744,0.152,0.104)$ \\
\hline
\end{tabular}

Table 27. Intuitionistic fuzzy decision matrix

The positive ideal and negative ideal solutions consisting of IF values are determined as shown in Table 28. After separation measures for each alternative are calculated as given in Table 29 , the closeness coefficient $\left(C C_{i}\right)$ of each alternative is determined as shown in Table 30 . Results of the IF-TOPSIS are as given in Table 30.

\begin{tabular}{cll}
\hline Criterion & IF positive ideal solution & IF negative ideal solution \\
\hline C1 & $(0.105,0.779,0.116)$ & $(0.374,0.488,0.137)$ \\
C2 & $(0.570,0.312,0.119)$ & $(0.362,0.527,0.111)$ \\
C3 & $(0.437,0.415,0.148)$ & $(0.310,0.554,0.136)$ \\
C4 & $(0.558,0.275,0.167)$ & $(0.148,0.701,0.151)$ \\
C5 & $(0.404,0.454,0.142)$ & $(0.274,0.588,0.138)$ \\
C6 & $(0.443,0.408,0.149)$ & $(0.353,0.516,0.131)$ \\
C7 & $(0.419,0.437,0.144)$ & $(0.260,0.627,0.113)$ \\
\hline
\end{tabular}

Table 28. Positive and negative ideal solutions of the alternatives for IF-TOPSIS

\begin{tabular}{lllll}
\hline & $\mathbf{A 1}$ & $\mathbf{A 2}$ & $\mathbf{A 3}$ & $\mathbf{A 4}$ \\
\hline $\boldsymbol{d}\left(\boldsymbol{A}_{\boldsymbol{i}}, \boldsymbol{A}^{*}\right)$ & 0.143 & 0.172 & 0.108 & 0.124 \\
$\boldsymbol{d}\left(\boldsymbol{A}_{\boldsymbol{i}}, \boldsymbol{A}^{-}\right)$ & 0.133 & 0.115 & 0.198 & 0.157 \\
\hline
\end{tabular}

Table 29. Separation measures of the alternatives for IF-TOPSIS

\begin{tabular}{lllll}
\hline & $\mathbf{A 1}$ & $\mathbf{A 2}$ & $\mathbf{A 3}$ & $\mathbf{A 4}$ \\
\hline $\boldsymbol{C C}_{\boldsymbol{i}}$ & 0.482 & 0.401 & 0.648 & 0.558 \\
Rank & 3 & 4 & 1 & 2 \\
\hline
\end{tabular}

Table 30. Closeness coefficient and ranks of the alternatives for IF-TOPSIS 
The results indicate that A3 is the best alternative in both CIF-TOPSIS and IF-TOPSIS methodologies as shown in Fig. 10 and the overall ranking obtained with IF-TOPSIS is A3, A4, A1, and A2, respectively. When CIF-TOPSIS was compared with IF-TOPSIS, it was seen that the first rank did not change, only the third and fourth ranks changed due to small changes in the closeness coefficients. This indicates that our proposed method is valid.

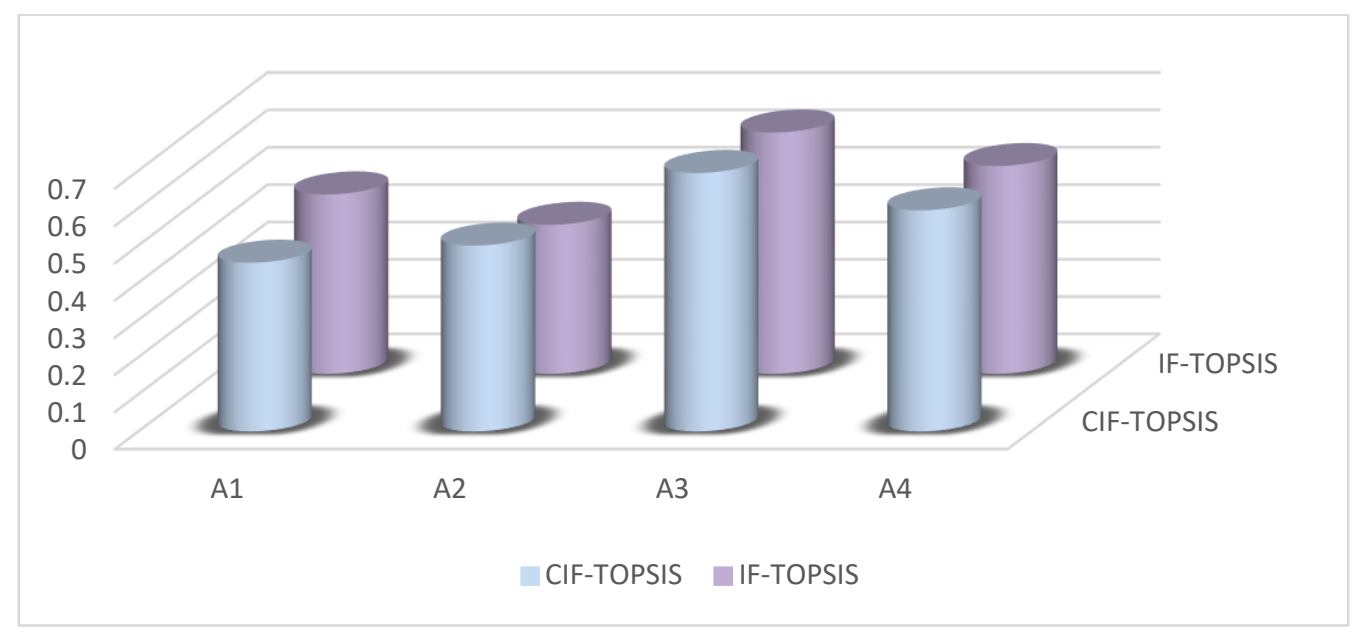

Figure 10. Results of comparative analyses

\section{Conclusion}

Circular intuitionistic fuzzy sets have the same idea as type-2 fuzzy sets that incorporate fuzziness to membership functions. In this study, circular intuitionistic fuzzy sets introduced by Atanassov (2020) have been employed to extend the TOPSIS method. Then, the proposed CIF-TOPSIS method has been implemented to a supplier selection problem.

Because of the inconsistencies between experts' membership degree assignments, CIFSs that consider the vagueness in the definition of membership functions have been employed in the fuzzy TOPSIS method. A sensitivity analysis has been conducted based on different criteria weights and it has shown that the results of the proposed approach are robust and reliable. Besides, a comparative analysis with intuitionistic fuzzy sets has been applied and the ranking results have been compared for a supplier selection problem. The validity of the method developed according to the comparison results has been proven.

For further study, different CIFS methods can be developed, such as triangular CIFSs, trapezoidal CIFSs, or interval-valued CIFSs instead of singleton CIFSs. Different MCDM methods based on CIFSs can be developed to compare to our proposed approach.

\section{References}

[1] Atanassov, K. (1986). Intuitionistic fuzzy sets. Fuzzy Sets System, 20 (1), 87-96.

[2] Atannasov, K. (1999). Intuitionistic Fuzzy Sets: Theory and Applications, New York: Heidelberg: Physica-Verlag. 
[3] Atanassov, K. (2020). Circular intuitionistic fuzzy sets. Journal of Intelligent and Fuzzy Systems, 39(5), 5981-5986.

[4] Bahadori, M., Hosseini, S. M., Teymourzadeh, E., Ravangard, R., Raadabadi, M., \& Alimohammadzadeh, K. (2020). A supplier selection model for hospitals using a combination of artificial neural network and fuzzy VIKOR. International Journal of Healthcare Management, 13(4), 286-294.

[5] Beil, D. (2009). Supplier Selection. Available online at: http://www-personal. umich.edu/ dbeil/Supplier_Selection_Beil-EORMS.pdf. Access date: 22 January 2021.

[6] Beg, I., \& Rashid, T. (2013). TOPSIS for hesitant fuzzy linguistic term sets. International Journal of Intelligent Systems, 28(12), 1162-1171.

[7] Biswas, P., Pramanik, S., \& Giri, B. (2016). TOPSIS method for multi-attribute group decision-making under single-valued neutrosophic environment. Neural Computing and Applications, 27(3), 727-737.

[8] Boran, F., Genç, S., Kurt, M., \& Akay, D. (2009). A multi-criteria intuitionistic fuzzy group decision making for supplier selection with TOPSIS method. Expert Systems with Applications, 36(8), 11363-11368.

[9] Budak, A., Kaya, İ., Karaşan A., \& Erdoğan, M. (2020). Real-time location systems selection by using a fuzzy MCDM approach: An application in humanitarian relief logistics. Applied Soft Computing, Article No. 106322.

[10] Büyüközkan, G., \& Göçer, F. A Novel Approach Integrating AHP and COPRAS Under Pythagorean Fuzzy Sets for Digital Supply Chain Partner Selection. IEEE Transaction on Engineering Management. (in press).

[11] Büyüközkan, G., \& Göçer, F. (2019). Smart medical device selection based on intuitionistic fuzzy Choquet integral. Soft Computing, 23(20), 10085-10103.

[12] Chan, Felix T. S., Kumar, N. M., Tiwari, K. H., Lau C. W., \& Choy, K. L. (2008). Global supplier selection: A fuzzy-AHP approach. International Journal of Production Research, 46(14), 3825-3857.

[13] Chen, T., Wang, H., \& Lu, Y. (2011). A multicriteria group decision-making approach based on interval-valued intuitionistic fuzzy sets: A comparative perspective. Expert Systems and Applications, 38(6), 7647-7658.

[14] Chen, T., \& Tsao, C. (2008). The interval-valued fuzzy TOPSIS method and experimental analysis. Fuzzy Sets and Systems, 159(11), 1410-1428.

[15] Cuong, B. (2014). Picture fuzzy sets. Journal of Computer Science and Cybernetics, 30(4), $409-420$.

[16] Elhassouny, A., \& Smarandache, F. (2016). Neutrosophic-simplified-TOPSIS multi-criteria decision-making using combined simplified-TOPSIS method and neutrosophics. 2016 IEEE International Conference on Fuzzy Systems (FUZZ-IEEE), 2468-2474. 
[17] Gündoğdu, F. K., \& Kahraman, C. (2019). A novel fuzzy TOPSIS method using emerging interval-valued spherical fuzzy sets. Engineering Applications of Artificial Intelligence, $85,307-323$.

[18] Gündoğdu, F. K., \& Kahraman, C. (2019). Spherical fuzzy sets and spherical fuzzy TOPSIS method. Journal of Intelligent \& Fuzzy Systems, 36(1), 337-352.

[19] Ho, L., Lin, Y., \& Chen, T. (2020). A Pearson-like correlation-based TOPSIS method with interval-valued Pythagorean fuzzy uncertainty and its application to multiple criteria decision analysis of stroke rehabilitation treatments. Neural Computing and Applications, 32(12), 265-295.

[20] Hussain, A., Irfan A. M., \& Mahmood, T. (2019). Covering based $q$-rung orthopair fuzzy rough set model hybrid with TOPSIS for multi-attribute decision making. Journal of Intelligent and Fuzzy Systems, 37(1), 981-993.

[21] Hwang, C., \& Yoon, K. (1981). Multiple Attribute Decision Making-Methods, New York: Springer.

[22] Liang, D., \& Xu, Z. (2017). The new extension of TOPSIS method for multiple criteria decision making with hesitant Pythagorean fuzzy sets. Applied Soft Computing Journal, 60, $167-179$.

[23] Lima-Junior, F. R., Osiro, L., \& Carpinetti, L. C. R. (2014). A comparison between Fuzzy AHP and Fuzzy TOPSIS methods to supplier selection. Applied Soft Computing, 21, 194-209.

[24] Liu, H., \& Rodríguez, R. (2014). A fuzzy envelope for hesitant fuzzy linguistic term set and its application to multicriteria decision making. Information Sciences, 258, 220-238.

[25] Mahmoudi, A., Sadi-Nezhad, S., \& Maku, A. (2016). An extended fuzzy VIKOR for group decision-making based on fuzzy distance to supplier selection. Scientia Iranica E, 23(4), 1879-1892.

[26] Memari, A., Dargi, A., Akbari Jokar, Ahmad, M. R., \& Abdul Rahim, A. (2019). Sustainable supplier selection: A multi-criteria intuitionistic fuzzy TOPSIS method. Journal of Manufacturing Systems, 50, 9-24.

[27] Opricovic, S. (1998). Multicriteria Optimization of Civil Engineering Systems. PhD Thesis, Faculty of Civil Engineering, Belgrade, 302 p.

[28] Park, J., Park, I., Kwun, Y., \& Tan, X. (2011). Extension of the TOPSIS method for decision making problems under interval-valued intuitionistic fuzzy environment. Applied Mathematical Modelling, 35(5), 2544-2556.

[29] Rezaei, J., Fahim, P. B. M., \& Tavasszy, L. (2014). Supplier selection in the airline retail industry using a funnel methodology: conjunctive screening method and fuzzy AHP. Expert Systems with Applications, 41, 8165-8179.

[30] Saaty, T. (1980). The Analytic Hierarchy Process: Planning, Priority Setting, Resource Allocation, New York: MacGraw-Hill, New-York International Book Company. 
[31] Saaty, T. (1996). Decision Making with Dependence and Feedback: The Analytic Network Process, RWS Publications, Pittsburgh.

[32] Sajjad Ali Khan, M., Abdullah, S., Yousaf Ali, M., Hussain, I., \& Farooq, M. (2018). Extension of TOPSIS method base on Choquet integral under interval-valued Pythagorean fuzzy environment. Journal of Intelligent and Fuzzy Systems, 34(1), 67-282.

[33] Sang, X., Liu X., \& Qin, J. (2015). An analytical solution to fuzzy TOPSIS and its application in personnel selection for knowledge-intensive enterprise. Applied Soft Computing Journal, 30, 190-204.

[34] Senapati, Y., \& Yager, R. (2020). Fermatean fuzzy sets. Journal of Ambient Intelligence and Humanized Computing, 11(2), 663-674.

[35] Smarandache, F. (1998). Neutrosophy: Neutrosophic Probability, Set, and Logic: Analytic Synthesis \& Synthetic Analysis, American Research Press.

[36] Tan, C. (2011). A multi-criteria interval-valued intuitionistic fuzzy group decision making with Choquet integral-based TOPSIS. Expert Systems with Applications, 38(4), 3023-3033.

[37] Torra, V. (2010). Hesitant fuzzy sets. International Journal of Intelligent Systems, 25(6), $529-539$.

[38] Xu, Z., \& Zhang, X. (2013). Hesitant fuzzy multi-attribute decision making based on TOPSIS with incomplete weight information. Knowledge-Based Systems, 52, 53-64.

[39] Yager, R. (2013). Pythagorean fuzzy subsets. In: Proceedings of the 2013 Joint IFSA World Congress and NAFIPS Annual Meeting, IFSA/NAFIPS 2013, 57-61.

[40] Yager, R. (2017). Generalized orthopair fuzzy sets. IEEE Transactions on Fuzzy Systems, 25(5), 1222-1230.

[41] Yu, C., Shao, Y., Wang, K., \& Zhang, L. (2019). A group decision making sustainable supplier selection approach using extended TOPSIS under interval-valued Pythagorean fuzzy environment. Expert Systems with Applications, 121, 1-17.

[42] Zadeh, L. (1965). Fuzzy set. Information and Control, 8(3), 338-353.

[43] Zadeh, L. (1975). The concept of a linguistic variable and its application. Information Sciences, 8 (3), 199-249.

[44] Zhang, X., \& Xu, Z. (2014). Extension of TOPSIS to multiple criteria decision making with Pythagorean fuzzy sets. International Journal of Intelligent Systems, 29(12), 1061-1078. 